\title{
The Role of Human Oral Microbiome in Dental Biofilm Formation
}

\author{
Wirginia Krzyściak, Anna Jurczak and \\ Jakub Piątkowski \\ Additional information is available at the end of the chapter \\ http://dx.doi.org/10.5772/63492
}

\begin{abstract}
Each surface of the human body, which stays in contact with the external environment, is covered by a layer of microorganisms. This layer-the human microbiomeis characterized by a high diversity of species and huge number of cells. Its name was proposed by Joshua Lederberg at the turn of the twentieth and twenty-first centuries and was originally referred to as a group of microorganisms colonizing a certain habitat. Currently, the term also defines a set of genomes of all organisms inhabiting a particular niche. Since the human microbiota affects many aspects of human health, it has become the subject of different studies. The use of sequencing methods enabled to obtain genetic material derived directly from the human environment with simultaneous explanation of mutual relationships between microorganisms inhabiting different ecological niches of human organism (i.e., commensal, symbiotic, and pathogenic microorganisms). It is hard to determine the amount of microbiota inhabiting human oral cavity because microbiota represents distinct anatomically limited ecological niches; for example, microbiota of tongue surface, cheek, teeth, palate, gingiva, and periodontal pocket. Apart from anatomical structure, other factors determine different composition of particular oral cavity microbiota. These factors are various qualities of saliva - a natural protective barrier ensuring maintenance of healthy condition of the oral cavity - and habits of diet and hygiene. Generally, bacteria are passively transported by flowing saliva toward teeth surfaces. In turn, the pioneering microorganisms initiating changes in the environment of oral cavity through the production and secretion of products of their metabolism induce mutual microbiota-biofilm interactions. The formation of biofilm of the plaque is a complex and rapidly evolving process in which several stages of development can be distinguished arbitrarily: (i) reversible binding of bacteria to solid surfaces, (ii) production of exopolysaccharide matrix, (iii) irreversible binding to the surface, (iv) maturation of biofilm structure, (v) disintegration and dispersion of an organized structure, and (vi) the formation of new habitats. An oral microbiome
\end{abstract}


analysis depending on the genotypic characteristics of the host, as well as its metabolic phenotype, will allow us to understand all these factors which are responsible for maintaining host-microbiota homeostasis. The formation of genetic maps (including host, as well as microbiota) of such environments and the detection of biofactors indicating the predisposition for a given disease may contribute to the development of new diagnostic methods in reference to individual persons, and thus individualized therapy.

Keywords: microbiome, pathogenicity, biofilm, antimicrobial peptides, dental plague

\section{Introduction}

\subsection{Formation of oral cavity microbiome}

Each of the human body surfaces, which are in contact with the external environment, is covered with a layer of microorganisms. This layer, called the human microbiome, is characterized by high species diversity and cell number. The term proposed by Joshua Lederberg at the turn of the twentieth and twenty-first centuries originally defined a group of microorganisms living in a certain habitat. Currently, italso defines a set of genomes of all organismsinhabiting a particular niche.

The human microbiome became the subject of many studies since it affects many aspects of human health. The use of sequencing methods enabled the correct identification of bacteria on the basis of obtained genetic material sourced directly from the human environment. This allowed explaining the mutual relationships between microorganisms inhabiting different ecological niches of the human body (i.e., commensal, symbiotic, and pathogenic microorganisms). In addition, particular attention is paid to the ability of microflora to modulate the expression of host genes. This phenomenon is a part of the cross-talk process. ${ }^{1}$

The oral cavity is one of the most numerous in terms of bacterial species diversity microbiome of the human organism [1,2]. Microbiome of the human oral cavity consists of difficult-to-determine number of microbiota representing anatomically limited distinct ecological niches, e.g., microbiota of the surface of the tongue, cheek, teeth, palate, gums, gingival pocket, etc. Except for the anatomical structure, the factors determining the variable composition of particular microbiota of the oral cavity are as follows: variable quality of saliva, being a natural protective barrier ensuring the maintenance of proper condition of the oral cavity, and also habits of diet and hygiene.

Environment of the oral cavity is subject to constant transformation depending on the age, appearance of first teeth, their extractions, carious lesions, dentures, fillings, edentulous and transitional changes that may be induced by diet, variable flow of saliva, and prolonged use

\footnotetext{
${ }^{1}$ Multidirectional network of connections that enables signal transfer and communication of bacteria with bacteria, bacteria with host, and host with bacteria, thus creating a comprehensive interactive ecosystem determining a wide variety of biological processes, including health or disease, between the host and their indigenous bacterial flora, leading to the molecular dialogue with the host cells.
} 
of antibiotics [3,4]. Environmental conditions such as temperature, salinity, availability of oxygen, nutrients, variable conditions of $\mathrm{pH}$, and redox potential may affect the ecosystem and contribute to changes in species composition of biofilms present in every place [5]. The formation of oral cavity microbiota begins at the moment of birth through the contact between the surface of the newborn's skin and mucous membrane of its mouth with mother's vaginal microbiota. In the case of birth by cesarean section, microflora is transferred from the mother's skin to the surface of the skin and mucous membranes of the newborn.

Immediately after the birth ( $<5 \mathrm{~min})$, the species of bacteria covering most of the body surface of the newborn (oral cavity, nasopharynx, skin, and intestines) are very similar to each other [6]. Children born vaginally have the microbiome of the oral cavity similar to the mother's vaginal microbiome, with the predominance of the following bacterial species: Lactobacillus, Prevotella, Corynebacterium, Staphylococcus, Streptococcus, Enterococcus, Bacteroides, and Sneathia spp., while children born via cesarean section have a flora similar to the one present on the mother's skin, with the dominance of the following bacterial species: Staphylococcus, Corynebacterium, Propionibacterium spp. belonging to the phylum such as Actinobacteria, Firmicutes, Proteobacteria, and Bacteroidetes (Figure 1) [7].

At the time of birth and in the following hours, newborn's oral cavity is massively exposed to microorganisms coming from the external world (breathing, breastfeeding, and contact with parents and medical staff). The process of permanent colonization of the oral cavity begins in the postnatal period. The so-called pioneering microorganisms determining the composition of the oral microbiome are established within 24 hours of birth. The most common colonizers of the oral cavity at this stage are gram-positive cocci, including Streptococcus (inter alia $S$. sanguinis, S. mitis and S. oralis, S. salivarius) and Staphylococcus genus (Figure 1) [8,9].

Pioneering microorganisms initiate the changes in the environment through the production and secretion of their metabolism products, which often enhances the growth of other species. For example, Streptococcus salivarius present in the oral cavity of the newborns, having the ability to adhere to epithelial cells and to produce extracellular polymers from sucrose, promotes the growth of other bacterial species including Actinomyces spp., which may adhere to the so-formed structure [8]. The increase in diversity of the formed complex produces a more stable structure of the oral cavity microenvironment.

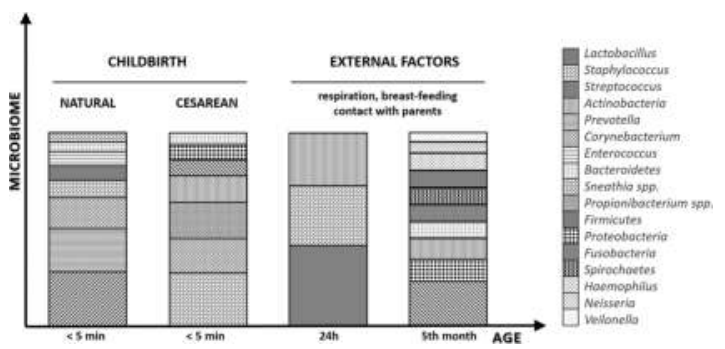

Figure 1. Human oral microbiome diversity during the age. 
During the first two months of the child's life, bacteria colonize only the surfaces of mucous membranes, and further species of microorganisms, which determine the changes within oral microbiome, occur with the eruption of deciduous teeth [10]. As the child grows, the oral microbiome is subject to evolution. In about fifth month of life, the microflora of infant's oral cavity shows a clear resemblance to the oral microflora of the mother due to environmental conditions that occur in the first months of life, in particular, through feeding, contact with other adults and children, contact with pets, hygiene, eating habits, etc. [11]. The microflora of the newborn's oral cavity is then composed mainly of bacteria, including those of the following six phyla: Firmicutes, Proteobacteria, Actinobacteria, Bacteroidetes, Fusobacteria, and Spirochaetes, among which the most widespread genera include Streptococcus, Haemophilus, Neisseria, and Veillonella (Figure 1) [11]. Interestingly, some of these microorganisms, such as S. mitis and S. oralis, produce proteases against immunoglobulin $(\operatorname{IgA})$, which specifically degrade the secretion of salivary IgA. Because of this feature, the microorganisms are able to survive in an environment rich in IgA, which is excreted with mother's milk [12]. Although infants during that period have lower number of microorganisms in the oral cavity than their parents, their species composition is richer [11].

The formation of a new ecological niche in the oral cavity environment is observed during the eruption of teeth, with the occurrence of new adhesion surfaces. It was believed that the colonization of Streptococcus spp. cariogenic strains, such as S. mutans, starts just at this stage at the moment of the appearance of hard surfaces. Caufield et al. have defined this moment as a so-called "window of infectivity" [13]. However, recent research overthrew the above view showing the presence of this species in edentulous children, which suggests that the soft tissues can act as a reservoir for pathogenic microorganisms such as, e.g., S. mutans [6]. This fact highlights the importance of oral hygiene habits in a child, even before the eruption of teeth.

At the age of three, oral microbiome seems to be complete, but its maturation process continues until adulthood [14]. The bacterial flora of the oral cavity in the child varies during the development of teeth: deciduous, mixed or permanent. The oral cavity microflora in children with deciduous teeth in relation to the other groups demonstrates a higher incidence of bacteria belonging to the following families: Pseudomonadaceae (Pseudomonas genus) Moraxellaceae (genera Acinetobacter Moraxella and Enhydrobacter), Enterobacteriaceae and Pasteurellaceae (Aggregatibacter genus). During the replacement of deciduous teeth on the permanent ones, population of bacteria belonging to the family Veillonellaceae (genera Veillonella and Selenomonas) and Prevotella genus is subject to an increase, whereas bacteria of the family Carnobacteriaceae (Granulicatella genus) decrease [14].

The population of oral cavity microorganisms in children aged 3-12 years is composed of the species of bacteria inhabiting different ecological niches, e.g., surface of the cheeks, gums, tongue, etc. One cannot talk about the microflora of teeth focusing only on the selected anatomical areas associated with certain bacterial species. Also the number of pathogenic species occupying specific ecological niches is not synonymous with the development of caries [15-18].

This is proved by the observations [19] that showed there was no presence of S. mutans in $10 \%$ of the examined children and adolescents (aged from 2 to 21 years) with caries. Also the 
contribution of other bacterial species-such as Lactobacillus, Veillonella, Bifidobacterium, Propionibacterium, acidic species independent of Streptococcus mutans (S. gordonii, S. oralis, S. mitis, and S. anginosus [18,20], Actinomyces, and Atopobium - in the development and progression of caries is suggested, which proves the influence of mixed bacterial flora on the development of dental caries. In the case of white spots the contribution of S. mutans is higher than in the control, but still quite low at a level up to $10 \%$ of the whole microflora [21]. Streptococcus (except S. mutans) and Actinomyces species are considered as the main reason of damage to the enamel. In the absence of $S$. mutans and Lactobacillus, initial enamel demineralization may be induced by the early colonizers, i.e., S. sanguinis, S. mitis, and S. oralis [18].

On the contrary, in case of the appearance of dentin lesion, the contribution of S. mutans represents about $30 \%$ of the total microflora, which indicates that this species is associated with advanced stage of caries. However, S. mutans was less common in caries progression, where Lactobacillus, Bifidobacterium, and Prevotella species dominated $[6,18,22]$. The studies evaluating the composition of microflora associated with early childhood caries show the share of bacteria of the following genera: Streptococcus, Veillonella, Actinomyces, Propionibacterium, Granulicatella, Leptotrichia, Thiomonas, Bifidobacterium and Atopobium, suggesting the lack of pathogenic species. The virulence of cariogenic bacterial population is correlated with the phenotype adopted for specified environment related to the acidic potential of bacteria that can induce the changes in the environment leading to the development of dental caries.

Under physiological conditions, oral cavity of children has a higher proportion of bacteria belonging to the following phylum: Firmicutes (genera Streptococcus, Veillonella, Lactobacillus, and Granulicatella) and Actinobacteria (genera Rothia and Actinomyces) and a smaller percentage of bacteria from phylum Bacteroidetes (genera Bacteroidales and Prevotella), Fusobacteria (Fusobacterium genus), Spirochaetes, and TM7 strain, compared to adults [14]. Interestingly, the share of cariogenic bacteria is also subject to an increase as the child grows. This change concerns the decrease in aerobic bacterial populations or facultative gram-positive cocci for the favor of relatively anaerobic gram-negative bacteria [17, 23].

Adolescence is a stage of major hormonal changes that accompany the enrichment of oral environment with a variety of nutrients, leading to the growth of certain groups of microorganisms, including gram-negative anaerobic bacteria and spirochete. This change in bacterial flora of oral cavity may be associated with an increased incidence and severity of gingivitis during the maturation [24].

The formation of a full oral microbiome takes several years, and in the case of certain surfaces, e.g., intestines, even longer. In the case of microbiota of oral mucosa, this process can be considered as complete after the eruption of permanent teeth.

Microorganisms colonizing the oral cavity live not only in the form of single cells (in the form of plankton), but are also capable of forming the clusters immersed in a mucilaginous extracellular matrix (ECM). In some diseases, the ability of bacteria to create a multidimensional, complex structure called "biofilm" plays a very important role. This structure adheres strongly to the surface so that the microbiome cells, particularly during the new biofilm formation, communicate with the cells of epithelium or mucous membranes by contact with 
their receptors sending various signaling substances $[25,26]$. In this way, a network of relationships is created, which results in both control of functioning of mucosal epithelial and immune cells present in the epithelium under the influence of microbial cells of the microbiome, as well as the control of microorganism populations and their metabolism by the cells of the host's organism². Only the presence and integrity of the microbiome are able to ensure the proper functioning of the cells of mucous membrane and skin surface, as well as protection against infections [2].

\section{Definition of pathogenicity and determinants of microorganism's pathogenicity}

An increasing number of opportunistic bacterial infections [27] have been reported in the past year. Microorganisms, which were previously considered as saprophytes incapable of causing human diseases, have now become an etiological factor in even serious conditions such as heart failure [28]. These microorganisms are referred to as "newly occurring pathogens" or "microorganisms on the newly acquired pathogenicity," which are generally called the emerging pathogens. These particular species develop pathogenicity due to evolutionary changes progressing slowly, as microorganisms adapt to new habitats, including the ecosystem, which is the human body.

Bacteria belong to Prokaryota and, thus, do not have complex genome repair and regulation systems; therefore they undergo changes at a much faster rate compared to the higher structured fungi (Eukaryota). In contrast to fungi, horizontal gene transfer does not occur in bacteria; this means that in practice the feature acquired by one strain can be transferred to other strains [29]. It is possible that an increased number of opportunistic infections recorded might be due to evolutionary adaptation of pathogenic strains to environmental changes $[30,31]$.

Aggressiveness of current medicine creates an increasing number of the gate infections. The use of antibiotics and other antimicrobial agents with a wide spectrum of action interferes with human microbiota ontogenesis. Elimination of one species involves an increase in the number of surviving species populations. Consequently proliferation mainly concerns opportunistic microorganisms that are often resistant to the applied chemotherapeutic agents.

The presence of a high content of sugar in the diet, particularly in beverages, facilitates the formation of dental plaques by microorganisms inhabiting the oral cavity. Demineralization acquired due to excessive acidity or constant contact of enamel with dietary sugars favors the infections. Patients from the so-called window of infectivity (between 19 and 31 months of age), patients during the eruption of teeth, patients with hypercalcemia, patients with different types of malocclusions subject to treatment, patients with disturbed functioning of the immune

\footnotetext{
${ }^{2}$ Host; organism, the parasite lives at the expense of (including parasitic bacteria). Parasite relationship with the host may be permanent or temporary.
} 
system, patients treated for systemic diseases and mentally handicapped, as well as patients with immunosuppression constitute the group to be at risk of opportunistic infections.

The features that determine the ability of a microorganism to cause disease, but which themselves are not required for their survival, are referred to as the determinants of pathogenicity [32]. Henderson et al. defined the determinants of pathogenicity as components of pathogens that are important in causing an infection in the host organism; they may include the factors vitally important for the microorganisms. A classic example may be the adhesins present on the bacterial cell surface that facilitate adhesion to receptors on the host cells surface, thus facilitating the colonization of bacterial species such as endotoxin lipopolysaccharides and gram-negative bacteria, which have a resistance towards the bactericidal activity of the complement and phagocytosis. On the other hand, the activity of heat-labile enterotoxin, for example, Escherichia coli, results in the activation of adenylate cyclase, increased intracellular cAMP concentration, and activation of protein kinase that phosphorylates cell proteins and is involved in ions transport. Increased cAMP concentration directly disturbs the function of the sodium potassium pump, which results in an excessive secretion of water and potassium ions from the cell and inhibition of the reabsorption of sodium ions and water. An excessive amount of water that is not absorbed is accumulated in the intestine, which increases intestinal passage and leads to the development of secretory diarrhea and tissues dehydration [33].

However, these definitions do not reflect the role of host's susceptibility to infection, indicating that only the features of the pathogen are causing disease. Consequently, only those organisms are microbe.

New definition of pathogenicity and pathogenicity determinants was created [34]. Pathogenicity of a specified microorganism is expressed as a range of damages that are caused by the microorganism itself and by the immune system as a response to the pathogen. They distinguished six classes of pathogens and are as follows.

Class I: This class of microorganisms damages only hosts with a weak immune response (with reduced host's immunity) and are commonly referred to as opportunistic or commensal; they do not cause damages to organisms with an undisturbed immune response; for example, damages due to Pneumocystis carinii are associated with the host response and those that are due to Pseudallescheria boydii are mainly associated with the growth of pathogens in host tissues (Figure 2).

Class II: This class of microorganisms causes damages both to people with impaired and normal immune responses. In the case of patients with weak immunity, damages are more severe and more frequent (Figure 2). Infections due to organisms such as Candida albicans and Cryptococcus neoformans are more often observed in individuals with weakened immune system and severe infections due to Streptococcus pneumoniae are usually associated with extreme age groups. This class also includes pathogens secreting toxins. For example, the toxins of Corynebacterium diphtheriae can cause damage immediately before the immune system responds, so the damage is regardless of the immune status of the patient.

Class III: This class of microorganisms causes damages to hosts both with impaired and normal immune responses. In both cases, the form of infection is similar (Figure 2), which distin- 
guishes that class from class II. For example in patients with impaired immunity, Histoplasma capsulatum causes infections that are associated with high mortality rate due to the proliferation of the cells to different organs; in patients with strong immune response, mediastinum fibrosis results from chronic inflammation.

Class IV: This class of microorganisms causes damages, especially in extreme cases-impaired immunity or in cases of immune system overactivity (Figure 2). This is a relatively small group of pathogens that causes symptomatic infections only in people with impaired immunity or in those with prolonged immune response. For example, Aspergillus fumigatus causes aspergillosis in patients with neutropenia or bronchial aspergillosis in patients chronically exposed to antigen.

Class V: This class of pathogens causes damages in any condition of the immune system, but mostly acute in the case of host's immune system overactivity (Figure 2). For example, infections of Salmonella and Campylobacter sp. do not usually cause any permanent changes, but in the case of increased immune response, they may develop into Reiter's syndrome, manifested by intestinal inflammation.

Class VI: This class of microorganisms causes damages only in the conditions of strong immune response of the host. This is a theoretical class, not reported so far (Figure 2); it includes inter alia a group of diseases of unknown etiology, for example, Crohn's disease or Whipple's disease. Helicobacter pylori is the closest to meet this criterion. The infection caused by this species is asymptomatic in most patients; however, in some of them, it leads to the development of ulcers and, consequently, to carcinogenesis. Damages are associated with factors dependent both on the pathogen and on the host.
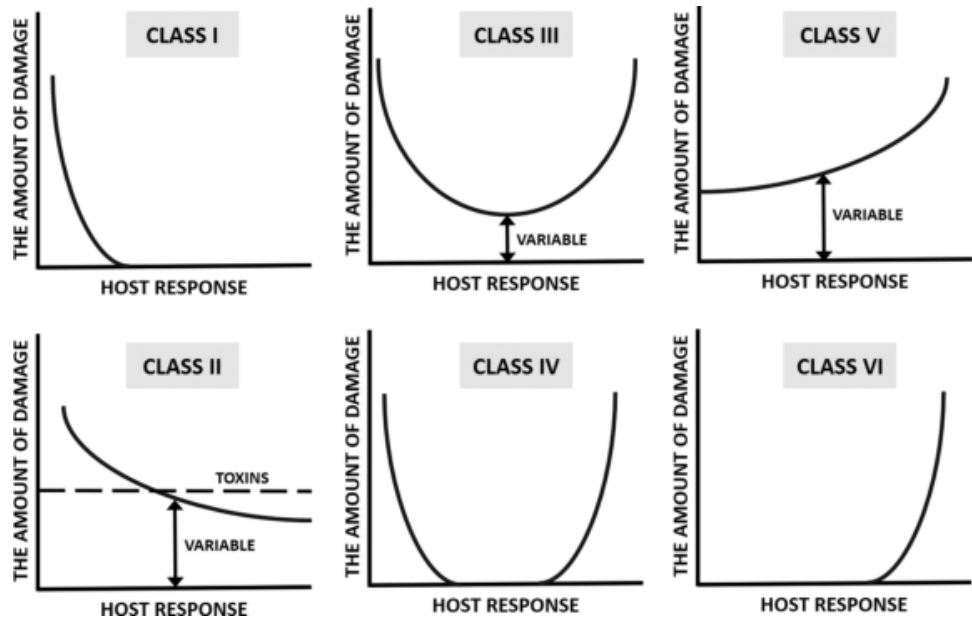

Figure 2. Pathogenicity presented as a function of the amount of damage and immune response of the host. Figure based on the study by Casadevall and Pirofski [34]. 
The state of host's immune defense is the main factor determining the course and cure of infection [34].

The determination of pathogenicity determinants for class I microorganisms based on the classification presented above poses some interpretation problem, since it seems that the key role in these infections is played by the condition of the host. Human is a complex ecosystem, in which bacteria-immune system homeostasis is observed in the physiological state. Bacteremia develops when this system is disturbed, usually through immunodeficiency and more rarely by the overexpression of bacteria pathogenicity determinants. However, most of the oral bacteria are rarely pathogens. So that even low-virulence pathogens have a minimum set of features that determine their pathogenicity and enables them to penetrate and proliferate in a host's body.

Writing about biofilm-pathogenicity determinant of Streptococcus genus-Kreikemeyer relates it with the discovery of long thread-like structures resembling pilus, which are located on the bacterial surface [35]. In S. pyogenes presented pilus are responsible for bacterial adherence and microcolonies creation on the surface of host cells, as well as aggregation itself, especially under the influence of saliva. These construction are involved in the interaction with pathogen and host; they are also causing bacteria clustering in the biofilm [36]. Pathogenicity of S. mutans is primarily associated with the ability to adhere to host cells and biofilm formation.

The bacteria in the biofilm resemble other organisms, for which the clustering is an evolutionary adaptation for survival. Bees and ants die if they are not in their "community;" similarly birds migrating for the winter organize themselves together to travel, and even most living mammals, starting from mice to Homo sapiens, are social organisms.

The complexity of relationships between microorganism and host, as well as differentiated expression of the features that determine the microorganism's pathogenicity, makes the pathogenicity an unpredictable phenomenon, since even a complete knowledge of hosts and microorganisms does not allow identifying all the possible interactions between them.

Due to certain specific characteristics of the host and microorganisms, all kinds of infectious diseases are often increasingly observed. Opportunities to travel around the world in a very short time not only contribute to the transfer of microorganisms in environments noninhabited by them but also extend their pathogenicity [37].

\section{Biofilm formation}

The most common diseases of the oral cavity, in which an important causative role is played by biofilm formed by microorganisms on the surface of teeth and gums, are dental caries and periodontitis. One of the main etiological factors of these diseases is Streptococcus mutans [3840]. 


\subsection{Stages of biofilm formation}

Biofilm formation is a multi-stage and very complicated process. There is a need for a number of relevant factors and conditions that must exist in the oral cavity, in order to assure the proper course of the whole process. However, five characteristic phases can be distinguished in it.

1. The initial phase of the microorganism adherence to a solid surface. S. mutans adheres to the tooth enamel and other materials such as tooth root or dental implant [41] using two mechanisms: sucrose dependent (based on the activity of glycosyltransferases and glucanbinding proteins) (Figure 3) and the sucrose independent (using interactions between adhesion particles of microorganisms and saliva agglutinins) (Figure 3) [42, 43].

2. Irreversible connection of bacteria with the surface, constituting the start of exopolysaccharide (EPS) matrix formation (EPS exopolysaccharide, which is the open architecture of nutritional channels, spaces, and other properties, including heterogeneity of the environment ( $\mathrm{pH}$ and oxygen gradients, co-adhesion) that forms the protection from the host defense factors and desiccation (Figure 3) [44].

3. Biofilm maturation, when the matrix is still being developed and another bacterial species join the biofilm [45]. The bacteria synthesize extracellular polymers (soluble and insoluble glucans, fructans, and heteropolymers), which are constituents of the plaque matrix (Figure 3). The presence of matrix is a feature of all the biofilms; however, it is much more than the chemical scaffold retaining the biofilm shape. The matrix is biologically active, retaining water, nutrients, and enzymes inside the biofilm structure.

4. Bacterial succession associated with the shift of initial dominance of the species of Streptococcus genus in the direction of the predominance of Actinomyces and other grampositive cocci. Newly occurring species of bacteria adhere to the previously attached pioneering species. The presence of one microorganism creates the ecological niches for other microorganisms, which facilitates their survival in the new favorable conditions. In 2003, this phenomenon, referred to as co-aggregation, was proposed by Rickard et al. [46]. An example of this phenomenon is the elimination of lactate by biofilm-forming streptococci, which becomes a source of carbon for the growth of Candida albicans. This, in turn, reduces the availability of oxygen to the level preferred by streptococci, thereby stimulating the growth of facultative anaerobic bacteria.

5. The formation of a mature biofilm is associated with growth-rate reduction of particular bacteria. The doubling of the bacteria amount occurs in 1-2 $\mathrm{h}$ in the initial stage of mature biofilm while in 1-3-day dental plate, it last 12-15 hours. A three-dimensional biofilm structure is formed. At this stage, the interactions between microorganisms (antagonism and synergism), i.e., their mutual influence on each other and microorganism-host interactions associated with the host's immune system plays the most important role not only in the formation of mature biofilm structure, but also in the disconnection of bacterial species from such formed structure, occupying subsequent ecological niches within the oral cavity microbiome [47-49]. Bacteria can "feel" the adverse changes in the environmental conditions and induce the genes related to active detachment. An example is 
Prevotella loescheii, which produces proteases hydrolyzing own adhesins related to fimbriae, responsible for co-aggregation with S. mitis.

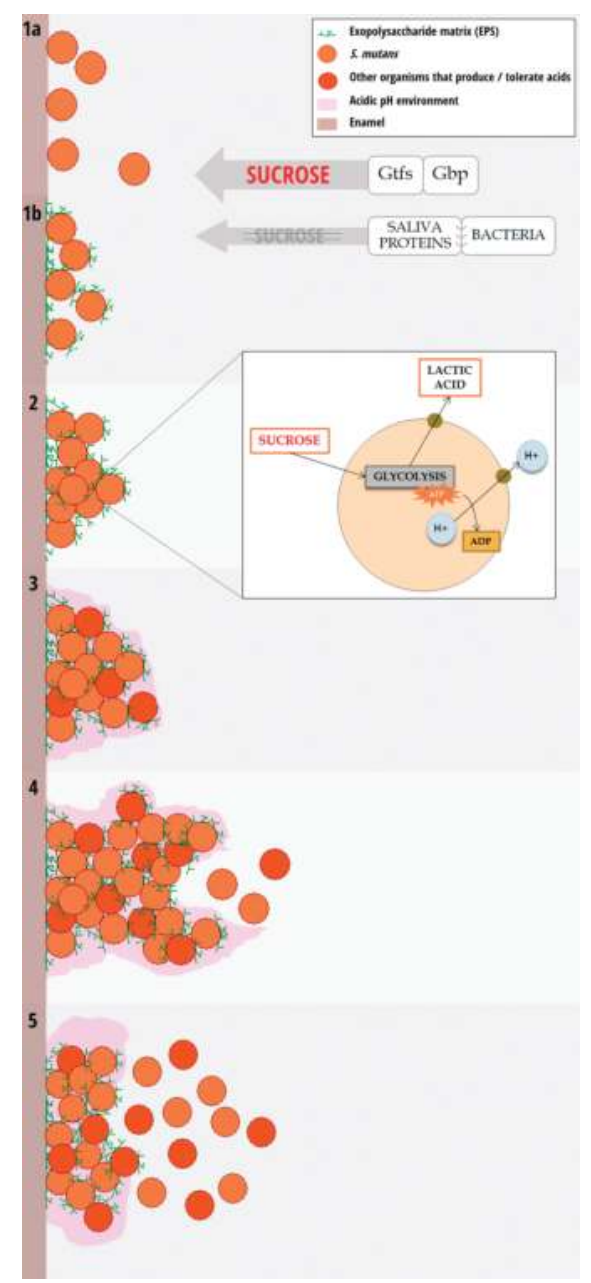

Figure 3. Stages of bacterial biofilm formation.

Mature biofilm structure is thus the result of the balance between the adhesion, growth, and removal of microorganisms. The development of plague as the biomass lasts up to the moment of reaching a critical size, i.e., when the shear forces limit further expansion; however, the structural development and reorganization may be continued. A classic example of a mature biofilm structure is dental calculus, which is mineralized dental plaque. It contains intracellular and extracellular deposits of minerals that grow around each bacterium and mineralized spaces coalesce and form a hard lodgment coated then with a layer of new bacteria. The 
calculus is observed both supragingival and subgingival, where it acts as an additional retention site for the accumulation of plaque causing gingivitis (which is related to the presence of, inter alia, above-mentioned Prevotella loescheii).

It is believed that in stages 4 and 5 of the biofilm formation (Figure 3), it is impossible to inhibit further formation of its structure. This is due to the interactions occurring between particular species accumulated in its structure and signals from the external environment (derived from microorganisms of oral cavity microbiome). At this stage, one can talk about hyperadditive synergism, during which the combination of the effects of particular species forming biofilm activity is observed.

Keeping in mind the general scheme shown in Figure 3, important aspects for the biofilm formation such as biocompatibility during microorganism adhesion [50], nutritional conditions [51] as well as hydrodynamic conditions [52], the type of surface (smooth, rough, and their combinations) $[53,54]$, and many other unexplained and undiscovered factors should be remembered.

\subsection{Factors affecting biofilm formation}

\subsubsection{Saliva and bacterial surface adhesins}

The process of biofilm formation begins with the coating of tooth surface by acquired enamel pellicle (AEP) $[44,55]$. The membrane is formed from the components of salivary origin (such as proline-rich proteins, amylase, lysozyme, histatin, peroxidase, mucin 2) and bacterial components (e.g., FtF GtF, lipoteichoic acid), specifically adsorbed on the surface of tooth enamel $[55,56]$. AEP constitutes the basis for biofilm formation by microorganisms that colonize the oral cavity [56]. Single cells of S. mutans or their aggregates connect to the membranes by two independent mechanisms: sucrose dependent and sucrose independent $[38,39,44]$.

The mechanism of adhesion (sucrose independent) involves an interaction between particles of S. mutans' adherence and AEP, which constitutes a diffusion barrier that protects the teeth against direct activity of organic acids [56]. Agglutinins are involved in the adhesion and aggregation by the interplay with adhesin P1 placed in bacterial cell wall [38-40, 57-59].

Salivary agglutinins play an equally important role in the process of biofilm formation as surface bacteria adhesins. The effect of salivary agglutinins on S. mutans' ability to form the biofilm was investigated in vitro $[38,40]$. In addition to the strain of wild type (WT), the scientists also used strains of $S$. mutans with mutated spaP gene, encoding protein P1, which allowed examination of the differences and interactions observed during the biofilm formation $[60,61]$.

The salivary proteins of high significance in the biofilm formation also include salivary proteins binding inorganic ions, mainly calcium. About 33\% calcium pool in the dental plaque is in free form, $17 \%$ is present in the bonds with phosphate ions and other organic anions. The remaining $50 \%$ is associated with specific proteins. The changes in protein profile may lead to calcium deficiency in dental plaque, and thus lead to the development of caries. Proline-rich 
proteins, statherines, and histatins (present in AEP); cysteine-containing phosphoproteins (in dental plaque); and low molecular peptides in saliva may play an important role as calcium ion binding sites. Furthermore, proline-rich proteins and statherines inhibit the precipitation of calcium phosphates. Thus, calcium-binding proteins play a significant role in the remineralization of tooth enamel, constituting these ions' reservoir [62]. Reduced amount of salivary proteins binding inorganic ions may consequently lead to an advantage of demineralization processes over remineralization processes and the development of caries disease.

\subsubsection{Presence of sucrose}

The discovery that the $\mathrm{pH}$ of the dental plaque is subject to a decrease after sucrose consumption and then returns to its original value [63] initiated intensive study on oral cavity microorganisms. They were the subject of research not only due to their importance in the health care, but also for the recognition of the number of interspecies interactions and the desire to know the behavior of microorganisms occupying a common ecological niche [45].

Sucrose-dependent way of dental plaque formation are the glucosyltransferases (Gtfs B, C, D) produced by $S$. mutans in combination with glucan-binding proteins (Gbp) [39, 55, 64].

Gtfs are responsible for the formation of glucans from sucrose. The synthesized glucans provide the possibility of bacterial adhesion to the tooth enamel and microorganisms to each other. This process allows forming microcolonies, which favors biofilm formation [55, 64].

In conditions in vivo, Gtfs adsorb very fast with salivary film (sHA). The highest connection to sHA is demonstrated by GtfC, which is a hydrophilic compound. However, it has a hydrophobic domain, which is responsible for the affinity to plaque. It enables overlapping of the interactions with saliva proteins contained in the salivary film such as lysozyme or $\alpha$-amylase. GtfB is glucosyltransferase, which in S. mutans is primarily responsible for interactions with other bacteria. It is responsible for the formation of highly differentiated microcolonies comprising the biofilm structure. Its activity is significantly increased in the presence of glucose [64].

The ability of GtfD to bind glucans is due to five of 65-five amino acids sequences repeated at the C-end of the chain. Glucosyltransferases binding other bacteria, even if they are not synthesizing their own glycosyltransferases [55, 65, 66]. Among the numerous polymers forming the plague $(\alpha-(1 \rightarrow 6)-, \alpha-(1 \rightarrow 4)-$, and $\alpha-(1 \rightarrow 3)$-glucans; $\beta-(2 \rightarrow 6)$-fructans $)$, a decisive role in etiopathology of tooth caries is played by $\alpha-(1 \rightarrow 3)$-glucan. This polymer constitutes $1.3-$ $1.4 \%$ of plate dry matter and exhibits several unique features that allow it to form a skeleton (matrix), i.e., it easily adsorbs to saliva or pellicle-coated enamel, promotes mutual sticking of bacteria (aggregation), and greatly improves the consistency of plaque. $\alpha-(1 \rightarrow 3)$-glucans are insoluble in water and have a fiber structure, which means that they are not dissolved and washed out by fluids of oral cavity. Moreover, $\alpha-(1 \rightarrow 3)$-glucans are neither subject to the activity of enzymes nor to those present in the oral cavity or produced by inhabiting its microorganisms, which ensures the stability and durability of the plaque [67].

Another component of sucrose-dependent mechanism is Gbps mediating in bacteria binding with glucans. There are four known types of that protein: GbpA, $-B,-C$, and $-D[39,55,64]$. 
$\mathrm{GbpC}$ protein (and possibly $\mathrm{GbpB}$ ) is associated with a cell wall of bacteria, and therefore is a specific receptor for glucans. All four types of the proteins play a role in microorganism adhesion and biofilm formation, but the protein GbpD seems to be the key one [55]. The studies using strains of S. mutans GS5 ( $g b p B$ gene deletion) and UACA2 (strain expressing an antisense RNA for gbpB gene) demonstrated, in turn, that the absence or mutation of GbpB encoding gene results in a change in cell shape and its slow growth [64]. This prevents normal development of the biofilm, which, instead of being a diverse, compact formation, becomes a creation formed of irregular cell clusters surrounded by a matrix of untypical structure.

Thus, sucrose plays a dual role in the formation of biofilm pathogenicity, provides a source for organic acid production by acidic species in dental plaque, and serves as a substrate for the production of extracellular polysaccharides (EPS) [48].

\subsubsection{Mechanisms of low $\mathrm{pH}$ tolerance}

The primary feature distinguishing cariogenic bacteria such as Streptococcus mutans and Lactobacilli is their ability to tolerate low $\mathrm{pH}$ of the environment, which results from the maintenance of intracellular $\mathrm{pH}$ homeostasis.

S. mutans species tolerance to low $\mathrm{pH}$ (acid tolerance response, ATR) is associated with a number of mechanisms regulating its cell physiology involving, inter alia, the changes in the synthesis and activity of cellular proteins and fatty acids [42, 68, 69]. One of the main mechanisms enabling $S$. mutans bacteria to survive at low $\mathrm{pH}$ is based on the increase in ATPase activity, mainly $\mathrm{F}_{1} \mathrm{~F}_{0}$-ATPase, proton pump, which removes $\mathrm{H}^{+}$ions outside the cell, thus contributing to the maintenance of intracellular $\mathrm{pH}$ at a level of about 7.5 [69-71]. This mechanism involves the active removal of $\mathrm{H}^{+}$ions from the cell through mentioned ATPase. This process requires energy input, which is obtained from the conversion of L-malate to Llactate (during malolactic fermentation, MLF). In addition to ATP, $\mathrm{CO}_{2}$ is also produced during this process, which additionally reduces the cytoplasm acidity, affecting the regulation of intracellular $\mathrm{pH}[70,71]$.

In the case of a prolonged period of starvation, during which the adequate nutrients such as sugars are not provided to bacteria, ATPase begins to act as ATP synthase, providing the cell with energy required for survival, and which the microorganism is not able to obtain from the food [72]. The neutralization of acidic products of metabolism in the cells additionally requires $\mathrm{CO}_{2}$, and ammonia resulting from the conversion of urea or arginine by urease or arginine deiminase system and agmatine deiminase system (AgDS) [70]. The result are products like ammonia and carbamoyl putrescine, which is subsequently converted to putrescine and $\mathrm{CO}_{2}$. These reactions are further stage comprising the maintenance of intracellular homeostasis in the conditions of the external environment decreased $\mathrm{pH}$.

Another process affecting low $\mathrm{pH}$ tolerance is the change in stress response proteins synthesis. The main products are present in the cell just after 30 minutes from the $\mathrm{pH}$ change to a lower value [73]. A large part of them demonstrate an increased glycolytic activity, which allows microorganisms to preserve the metabolic ability under new conditions [69, 70]. Another concept of S. mutans tolerance to low $\mathrm{pH}$ suggests a role of the cell membrane in that 
process $[70,71,74]$. The expression of fabM gene responsible for the synthesis of monounsaturated fatty acids is subject to the changes in an environment of acidic $\mathrm{pH}$, which increases their share in cell membrane structure. The changes in the membrane lipid profile results in a decrease in its permeability, which allows for more efficient maintenance of $\mathrm{H}^{+}$ions out of the bacterial cell [74].

An additional mechanism supporting ATR is the biofilm formation, which focuses in its structure the clusters of microorganisms of different species, additionally protecting them with EPS matrix. As demonstrated by Welin-Neilands and Svensäter [69], the cells of S. mutans in the planktonic phase are seventy thousand times more sensitive to low $\mathrm{pH}$ compared to the biofilm-forming cells of that microorganism. This feature is explained by an increased tolerance to the low $\mathrm{pH}$ of the cells adhering to the surface. Microorganisms grouped in this way, mutually affecting their metabolism, weaken the activity of produced glycolytic enzymes, which results in a decrease in the production of acidic substances that lower the $\mathrm{pH}$ of the environment [69]. A large role in the biofilm resistance to acidic conditions in the oral cavity is played by glucans as discussed below, which slow down the diffusion of hydrogen ions into the biofilm [75].

Other microorganisms resist the low $\mathrm{pH}$ of the environment by an increase in the gene expression associated with the production of bases, e.g., S. salivarius activates urease enzyme which degrades urea into ammonia, while S. sanguinis system of arginine deiminases causing arginine decomposition to ornithine, carbon dioxide, and ammonia at lower $\mathrm{pH}(4.0)$ than that enables the growth and may cause glycolysis ( $\mathrm{pH} 5,2)$.

Streptococcus mutans can also use branched-chain amino acid (BCCA) biosynthesis as one of the ways to deal with cytoplasm acidification $[42,70]$. In this mechanism, S. mutans redirects pyruvate formed in glycolysis for the pathway of biosynthesis of amino acids belonging to the group of BCAA. This reduces the amount of substrate for organic acid production, mainly lactic acid. The initial reaction in the biosynthesis of valine and leucine amino acids is acetylacetonate formation by condensation of two pyruvate molecules. $\alpha$-keto acid is produced during further reactions, which finally is converted by aminotransferase to the BCAA. In addition, $\mathrm{NH}^{3+}$ ion is secreted during isoleucine biosynthesis, also belonging to BCAA, whose binding with $\mathrm{H}^{+}$causes the formation of ammonia and alkalization of cytoplasm [76]. Santiago et al. (2012) obtained an increase in expression ilvE gene encoding a BCAA aminotransferase (ILvE) in S. mutans in response to environment acidification. In addition, they demonstrated that the activity of membrane ATPase is subject to a decrease in microorganisms lacking genes for ILvE, which is one of the main mechanisms to maintain $\mathrm{pH}$ homeostasis in the bacterial cell [76, 77].

Another important mechanism protecting Streptococcus mutans against the harmful effect of low $\mathrm{pH}$ is the permeability of the cell membrane. During the adaptation to an acidic extracellular $\mathrm{pH}, \mathrm{S}$. mutans can change fatty acid composition in the cell membrane to prevent the passive penetration of $\mathrm{H}^{+}$ions into the cell. In turn, the amount of monounsaturated fatty acids and long-chain fatty acids is subject to an increase, which reduces membrane permeability [42, $68,70]$. 
The change in the activity of numerous cellular proteins is observed during the adaptation to stress conditions. The study conducted by Gong et al. demonstrated that during the adaptation to environment acidification $(\mathrm{pH}=5.5)$ [68], S. mutans alters the expression of about $14 \%$ of their genes, most of which are genes whose expression is subject to an increase (e.g., encoding subunits of membrane proton pump; two-component regulatory systems: $c 0 m D, c o m E, c i a H$, ciaR, and others; transcription factors; protein transporters, e.g., P-type ATPase responsible for inorganic ion transport). A significant part of genes of an increased expression is the genes that protein products exhibit glycolytic activity, which protects microorganisms against a decline in metabolic ability under new conditions [70].

\subsubsection{Carbohydrate metabolism}

In oral cavity conditions, cariogenic bacteria S. mutans are characterized by altered metabolism compared to the cells of physiological flora. It is based on glycolysis, which also occurs in presence of oxygen (a phenomenon known as the Warburg effect). The low concentration of oxygen $(<2 \%)$, i.e., hypoxia inside the biofilm, increases an expression of genes encoding glycolytic enzymes and inhibits the oxidative phosphorylation.

Carbohydrate metabolism is one of the key metabolic pathways that subject to changes during mixed biofilm development. It was demonstrated that the amount of synthesized glycolytic enzymes, including glucokinase, aldolase, phosphoglycerate mutase, and pyruvate kinase, is subject to an increase [77]. Therefore, S. mutans is more resistant compared to other streptococci to glycolytic enzyme inactivation in a response to the lowered $\mathrm{pH}$ of the environment. This may be due to an increased amount of ATP produced during glycolysis, and consequently, increased proton removal by $\mathrm{H}^{+}$-ATPase $[78,79]$. Glycolytic enzymes are sensitive to low $\mathrm{pH}$, which results in a decrease in their activity when the $\mathrm{pH}$ inside the cell is lowered. The optimum $\mathrm{pH}$ for glycolysis process is neutral $\mathrm{pH}(\mathrm{pH}=7)$, an increase in the activity of glycolytic enzymes during ATR can therefore be explained by the need to overcome the inhibitory effect of environment acidification in relation to the metabolic activity [77]. Furthermore, when the bacterial cells adapt to the new conditions, the optimum $\mathrm{pH}$ for the glycolysis is reduced and the process rate is increased [42]. This means that $S$. mutans may continue its metabolism, even when the external $\mathrm{pH}$ falls below 4 , which for most microorganisms do not have ATR mechanisms causing stop their metabolism [42].

The glycolytic activity increases in the newly formed biofilm (a few hours), which is caused by an increased activity of the processes needed to adapt to new environmental conditions, requiring energy inputs in the form of ATP. However, the glycolytic activity of enzymes decreases with dental plaque biofilm aging. The probable cause is the desire to avoid further acidification of the environment, when biofilm becomes thicker. Reduced rate of glycolysis process, combined with decreased rate of cell growth in the biofilm, can make the structure more stable and resistant to external factors [78].

Glycolysis provides not only ATP, but also intermediate products involved in anabolic processes [77]. An example would be an increased activity of NADP-dependent glyceraldehyde-3-phosphate dehydrogenase. This enzyme bypasses the stage of first ATP molecule formation, in order to provide the reduced form of nicotinamide adenine dinucleotide 
phosphate (NADPH), which is necessary in the reduction processes. This is a significant reaction since $S$. mutans has neither the enzymes of oxidative pentose pathway portion nor transhydrogenase, which would generate NADPH [77]. In addition, the expression of other enzymes, transketolase, increases in the conditions of environment acidification. This enzyme redirects the two intermediate products of glycolysis, glyceraldehyde 3-phosphate and fructose 6-phosphate, to the non-oxidative part of the pentose pathway, and consequently, for the pathway of nucleotide biosynthesis needed for DNA synthesis [77].

Of the three enzymes involved in the final conversion of 3-phosphoglycerate to pyruvate, two of them demonstrate higher expression in $\mathrm{pH}=5$ than at a neutral $\mathrm{pH}$. The first of them, phosphoglycerate mutase, exhibits more than twofold increase in expression, while the activity of pyruvate kinase increases nearly threefold [77]. Pyruvate kinase, the last of the enzymes involved in glycolysis, is considered as an enzyme conditioning the rate of the whole process since it is activated by glucose-6-phosphate, a substrate of glycolysis in S. mutans.

Len et al. demonstrated nearly 93\% reduction in the activity of the enolase, an enzyme that converts 2-phosphoglycerate into phosphoenolpyruvate (PEP) [77]. PEP is a precursor of pyruvate, which is involved in carbohydrate transport inside the bacterial cell in phosphoenolpyruvate-sugar phosphotransferase system (PEP-PTS), where it plays a role of phosphate donor [80]. In the conditions of reduced $\mathrm{pH}$, the amount of PEP produced is subject to a decrease as a consequence of reduced enolase activity. However, the amount of pyruvate produced by pyruvate kinase increases concurrently, which may indicate the conversion of 2phosphoglycerate to pyruvate without phosphoenolpyruvate accumulation [77]. In addition, PEP is also an inhibitor of lactate dehydrogenase, an enzyme that converts pyruvate to lactic acid. Therefore, a decrease in PEP amount results in an increased production of lactic acid at low $\mathrm{pH}$, which was confirmed in the studies $[69,77]$.

Increased expression of some glycolytic enzymes, e.g., glyceraldehyde 3-phosphate dehydrogenase, enolase, phosphoglycerate kinase, or aldolase, can be explained by their dual function, which is related to adhesion to the substrate [81]. These enzymes are found on the bacterial cell surface of many species of Streptococcus genus [69]. The study conducted by Ge et al. revealed the presence of enolase on the surface of $S$. mutans, and the ability of that enzyme to bind to salivary mucin MG2, as well as plasma plasminogen [81]. Thus, enolase acts not only as a glycolytic enzyme, but also as the surface adhesin facilitating cell adhesion to the pellicle acquired on the surface of the tooth. Double function of enolase may explain the results demonstrated almost a twofold increase in the expression of the genes for enolase during the initiation of bacterial biofilm formation. Due to the presence of surface enzymes on the bacterial cells, S. mutans is considered, next to the streptococcus of viridans group, as one of the etiological factors of bacterial endocarditis or bacteremia [82, 83]. Also rare cases of recurrent bacteremia in women with Sjogren's syndrome were noted [84]. In addition to endocarditis and bacteremia, S. mutans induced sepsis [85], and it was also the etiologic factor of other systemic diseases [86]. Also, a rare case of retroperitoneal abscess caused by S. mutans was described [87]. 


\subsubsection{Nitrogen metabolism}

Metabolism of nitrogen compounds is related to an activity of many endopeptidases and exopeptidases. S. sanguinis, S. gordonii, and some lactobacilli species release arginine from peptides decomposing it using arginine deiminase to ammonia, ornithine, and carbon dioxide with the release of energy. Urea present in saliva at a relatively high concentration (200 $\mathrm{mg} / \mathrm{L}$ ) is decomposed by certain bacteria having enzyme urease (e.g., S. salivarius, A. naeslundi) to carbon dioxide and ammonia. This example is proof of the existence of interspecies interactions associated with the ability of some bacterial species to the reduction of the environment acidity through the production of ammonia, creating more favorable conditions for the survival of bacteria sensitive to low $\mathrm{pH}$. Such ability is demonstrated by microorganisms such as Fusobacterium nucleatum and Prevotella intermedia, which, through the production of ammonia during glutamate and aspartate fermentation, enable the growth of sensitive species such as, e.g., Porphyromonas gingivalis [88].

\subsubsection{Oxygen metabolism}

Expression of S. mutans pathogenicity determinants and biofilm formation in specific conditions of the oral cavity can be modulated, inter alia, by the environment and the presence of oxygen [39].

The culture of $S$. mutans strains under aerobic conditions produces $80 \%$ reduction in bacterial ability to biofilm formation [38]. The availability of oxygen is the causative agent of the changes in the bacterial cell surface composition, as well as modifications that occur in autolysin production and specific system of signal transduction VicRK. The production of autolysin AtlA is conditional by an expression of gene SMu0629 demonstrating oxidoreductase activity. An increased expression of this gene can be observed under aerobic conditions, and therefore the overproduction of autolysin AtlA, which inhibits biofilm formation. Transducer of kinase VicK constitutes a system regulating the expression and activity of autolysin AtlA. The study on the strains mutated for the gene SMu0629 and vicK was conducted in order to confirm the changes in autolysin affected by oxygen. Strains with the removal of the above-mentioned genes adapted better to the aerobic conditions and showed a greater ability to biofilm formation compared to the parent strain UA159 [89].

Multi-species biofilm formation is conditioned by physiological relationships favoring the connection of microorganisms with different environmental requirements or different type of metabolism. An example of such relationship is oxygen absorption by the early colonizers such as Neisseria genus, providing thus favorable conditions for the growth of the absolute anaerobic bacteria like Porphyromonas gingivalis [78]. Another example of interspecies cooperation in biofilms is an increase in expression of gene amyB for $\alpha$-amylase in Streptococcus gordonii caused by the co-aggregation with Veillonella atypica species. Decomposing carbohydrates, such as $\alpha$ amylase, contribute to the formation of acidic end products of $S$. gordonii metabolism, mainly lactic acid. The resulting acid then becomes a source of carbon for $V$. atypica, bacteria, which itself cannot ferment carbohydrates [90]. 
This example proves that the existence of the relationship between oral cavity bacterial microbiome, inter alia, absolute anaerobes, which occur at different locations of the oral cavity, and, as evidenced by the studies, can survive oxygen exposure due to the interactions with the bacterial biofilm species, metabolizing oxygen and having appropriate enzymes removing toxic products of free radical reactions.

\subsubsection{Production of intracellular polysaccharides}

Since bacteria found in the oral cavity are subject to continuous "feeding" and "hunger" cycles with respect to dietary sugar supply, the resident microflora develops, as a consequence, a mechanism for carbohydrate storage. They help avoid the lethal effects of excessive amounts of intermediate products of intracellular glycolysis and provide a source of carbon and energy during the "starvation" period. Intracellular polysaccharide (IPS) repositories are created and are a source of energy during starvation; they can promote tooth decay, by extending the time in which the teeth are exposed to organic acids [48, 91]. IPS are high molecular polymers containing $\alpha-1,4$ and $\alpha-1,6$-glycosidic bonds in their molecules, which are readily metabolized in the absence of other carbohydrate sources.

It was proved that the strains of $S$. mutans, which have an increased repository of these polysaccharides, are considered to be more cariogenic than other strains of the microorganisms colonizing the dental plaque. The studies demonstrated that organic acid production by S. mutans from intracellular substrates resulted in an increased and prolonged drop in environment $\mathrm{pH}$, leading to the acceleration of demineralization processes [62].

\subsubsection{Production of extracellular polysaccharides (EPS)}

EPS promote biochemical and physiological changes in bacterial biofilm matrix. EPS allow adhesion and clustering of microorganisms accumulated in the biofilm structure, and they provide structural integrity and stability and increase the biofilm biomass, matrix acidity, as well as reduce the concentration of inorganic ion. With an access to sugars, especially sucrose, EPS are produced in a continuous manner, which, as a consequence, leads to the formation of bacterial microcolonies and then three-dimensional structures [48]. Polysaccharide EPS matrix provides the protection for bacterial microcolonies present in the biofilm against adverse external factors, including bactericides or host's defense mechanisms. It also provides the protection for all kinds of microorganisms contained in the biofilm, creating environmental niches in which they can communicate with each other, adapt to the conditions, and even change the surrounding microenvironment. The matrix of EPS biofilm may also affect the availability of nutrients, metabolites, or signaling substances [92]. Moreover, EPS increases the mass and porosity of biofilm matrix, allowing more nutrients to diffuse into the surface of the teeth. Therefore, the deeper layers of biofilm are exposed to acidic $\mathrm{pH}$ activity, increasing thus the risk of caries [62]. In addition, the polysaccharide matrix is a place of accumulation of organic acids produced from carbohydrates fermented by acid-forming bacteria, including streptococci from mutans group and bacteria of Lactobacillus genus [55]. It constitutes an impermeable barrier for the buffering activity of saliva, which causes the formation of acid niches, mainly inside the biofilm structure [48]. Due to a limited diffusion to and from biofilm, 
it is possible to collect the nutrients or metal ions inside it that are necessary for microorganism survival and to reduce the penetration of external bactericidal substances, and also antibiotics [55]. The composition and structure of biofilm matrix may change over time, and this may be due to both effects of bacterial populations and microenvironment factors. An example can be the presence of extracellular DNA (eDNA), which enhances the adhesion of S. mutans to biofilm surface. The eDNA is a component of the (ECM) and is formed from chromosomal DNA during the processes such as autolysis or active secretion [93]. It is incorporated in the matrix, affecting the biofilm architecture and development. It was demonstrated in the studies that eDNA is involved in several stages of biofilm formation, including the initial bacterial adhesion, aggregation, and mechanical stabilization of biofilm structure. eDNA is also involved in genetic competence, the process in which genetic information can be transferred from one bacterial species to another related one. This is a kind of horizontal gene transfer, inter alia, encoding virulence factors or genes of resistance to bactericidal agents [94].

\subsubsection{Proteases}

Also other features of $S$. mutans, such as production of proteases, which can decompose the proteins derived from the host, are not without significance [95]. Some examples include collagenases, proteins degrading collagen in the dentin and teeth cement, which may in turn lead to caries of the root surface of the tooth [96], and proteases degrading the components involved in host's immune response, e.g., proteases IgA1, which degrade secretory immunoglobulins A1 (sIgA1) present in the saliva. Secretory antibodies IgA1 are the first line of host's defense against bacterial agents, preventing their adhesion and colonization on tooth surfaces. These antibodies block surface adhesins AGI/II [97-99]. In the conditions prevailing in the oral cavity, the expression of pathogenicity determinants, in particular species of bacteria, both those forming oral cavity microbiome and those contained in the biofilm, is affected by both the environment in which the biofilm grows and the influence of accompanying bacterial flora.

\subsection{Mixed biofilm}

The interactions observed between microorganisms of oral cavity microbiome is another major factor affecting the development of the biofilm $[39,100]$. The interactions that occur between the microorganisms can result in both acceleration and inhibition of this process. This way, the pathogenicity of $S$. mutans depends not only on the environmental conditions of the oral cavity, but also on the composition of its bacterial flora.

In a response to rapidly changing environmental conditions of the biofilm, such as $\mathrm{pH}$, the content of EPS, or the amount of available nutrient substrates, bacteria had to develop molecular adaptation pathways that would ensure their survival and optimal metabolism. The interactions that occur between the microorganisms can result in both acceleration and inhibition of this process. Microorganisms can change the expression of their genes and communicate with each other in response to the density of their distribution. "Quorum sensing", i.e., density signaling, "overcrowding sense", is based on the interactions between chemical molecules, autoinducers and their receptors. In the case when the concentration of autoinduc- 
er in the local environment reaches the threshold concentration, it causes an induction of corresponding genes expression, concerning, inter alia, the division and differentiation of cells, virulence (e.g., bacteriocins), responsible for the production of enzymes (e.g., glycosyltransferases). Communication can occur between the cells of the same or different species. This system differs in gram-positive and gram-negative bacteria. Autoinducers of gram-positive bacteria are peptide molecules, whereas in gram-negative bacteria, these functions are played by acylated homoserine lactone (HSL) [101].

Quorum sensing (QS) in S. mutans is mediated by a two-component regulatory system (TCS) ComDE. ComDE genes are included in the operon com $C D E$, which together with operon $\operatorname{com} A B$ play a significant role in the biofilm formation, bacteriocin production, response to stress conditions, e.g., low $\mathrm{pH}$ of the environment, and in the so-called genetic competence. This process involves the ability of bacteria to the heterologous DNA uptake and is quite often found in the biofilm environment [102]. Competence stimulating peptide (CPS) is an autoinducer in QS system in S. mutans, and its protein precursor is the product of gene comC. CPS is a signaling molecule and is secreted outside the cells of the bacteria by $\mathrm{ABC}$ transporter, $\operatorname{com} A B$ gene product. Once a sufficient threshold concentration in the biofilm environment is reached, CPS mediator combines with the bacterial cell surface receptor ComD, which is a membrane histidine kinase. After joining to ligands, the receptor is subject to autophosphorylation with the participation of ATP. Then, the signal is transmitted to the response regulator (ComE), which after conformation change affects the transcription of genes $\operatorname{com} A B, \operatorname{com} C D E$, and $\operatorname{com} X$. ComX is an alternative sigma subunit of RNA polymerase that recognizes other promoter sequences and determines the level of expression of the genes associated with the genetic competence and response of the increase in the density of the microorganism population [103104]. Competences stimulating peptide (CSP) is involved in the regulation of bacterial biofilm formation, which was demonstrated constructing the mutants lacking genes com $C$ and comDE. Strains of $S$. mutans devoid of gene comC formed the biofilm with altered structure compared to the wild strains, while the biofilm of mutants of genes comDE had changed the structure and significantly decreased biomass. It was also demonstrated that the presence of CPS increases the expression of genes for glycosyltransferases $(g t f B / C / D)$, fructosyltransferases $(f t f)$, and glucan-binding protein B, i.e., the factors involved in the biofilm formation of $S$. mutans $[78,105]$. Interestingly, other studies demonstrated that an excess of CPS may contribute to the death of bacterial cells. This might be a way of a selective control of $S$. mutans survival in mixed biofilms and its virulence control $[104,105]$, but on the contrary, bacterial cell death leads to the release of chromosomal DNA into the biofilm matrix and provides the nutrients, which increases the ability of bacteria to survive in the biofilm [42]. Zhang et al. pointed out the role of CPS in the late stages of the biofilm formation, i.e., its maturation without affecting the growth and division of bacterial cells [104].

An important signaling molecule participating in interspecies communication is autoinducer AI-2-affecting the expression of $g t f B$ and $g t f C[39,55]$. It is produced by both gram-positive and gram-negative bacteria. It is formed during the spontaneous conversion of 4,5-dihydroxy-2,3-pentanedione, whose biosynthesis is catalyzed by LuxS protein. LuxS protein, the product of $\operatorname{lu} x S$ gene, is present in many species of bacteria observed in biofilms (dental 
plaque), including S. mutans, S. gordonii, S. oralis, L. casei, and P. gingivalis. LuxS enzyme plays a dual function, except AI-2synthesis, it also participates in the conversion of toxic S-adenosyl-L-homocysteine to homocysteine [106]. AI-2 regulates, inter alia, the biofilm formation, tolerance of oxidative stress or stress induced by environment acidification, and the expression of virulence factors in response to the increase in bacterial density in the local environment, e.g., the production of bacteriocins [39, 106-108].

Bacteria present in mixed biofilm can not only interfere with each other on the changes in gene expression, but they may also provide each other with plasmids, e.g., antibiotic resistance genes [78]. Among the S. mutans species, inter alia, erythromycin or kanamycin resistance gene (gene aphA3) can be transferred, which causes the changes in above bacterial phenotype in the direction of multidrug resistance phenotype, impeding an effective targeted therapy [82, 107]. An example of such plasmids may be a new transposon vector called "pMN100," containing, among others, selective kanamycin resistance gene, an aminoglycoside antibiotic [82]. As the multi-species biofilm develops, S. mutans increases the expression of genes related to the synthesis, alterations, and adhesion of EPS, particularly genes for surface enzymes, glycosyltransferases. These changes can be caused by the presence of other bacterial species in the biofilm $[109,49]$. There is also an increase in the activity of enzymes decomposing extracellular glucans, mainly dextranases. Dextranase, hydrolyzing $\alpha-1,6$-glycosidic bonds during the synthesis of glucans, leads to an increase in the ratio between $\alpha-1,3$ and $\alpha-1,6$ bonds, resulting in an increase in insoluble matrix components. Due to its activity, this enzyme also provides the primers for insoluble glucan production. Moreover, the degradation of soluble glucans and fructans (via fructanase) provides the substrates for organic acid production, thus leading to acidification of biofilm microenvironment [48, 110].

Also, an expression of factors involved in response to stress related to a decrease in environment $\mathrm{pH}$ is increased in mixed biofilms. This starts a complex mechanism of ATR, comprising many processes, whose aim is to maintain the $\mathrm{pH}$ at an appropriate level, inter alia, the activity of proton pumps is subject to an increase, e.g., F1F0-ATPase, whose task is to remove $\mathrm{H}^{+}$ions outside the cell, an increase also involves fatty acid biosynthesis, BCAA metabolism, and other processes that were mentioned in the section concerning factors of $S$. mutans pathogenicity (Section 2.3) [48, 109].

Also a decrease in the expression of proteins aimed in repairing DNA was observed in a mixed biofilm, which may indicate a decreased DNA susceptibility to damage, which is caused, e.g., by chemical agents or radiation [111]. In turn, the share of proteins involved in the synthesis is increased, inter alia, ribosomal proteins, including factors affecting translation initiation and elongation (e.g., aminoacyl-tRNA synthetase) or factors involved in the translation elongation, e.g., factors Tu and G [77], proteins involved in protein folding and secretion, e.g., chaperone protein DnaK, whose task is to prevent erroneous folding of proteins and their aggregation [42,77]. Also the number of proteins involved in biosynthesis of amino acids and fatty acids is subject to an increase, e.g., BCAA aminotransferase [76], or fabM, involved in the production of monounsaturated fatty acids [42]. The change in membrane lipid profile results in a decrease in its permeability, which allows more efficient maintenance of $\mathrm{H}^{+}$ions outside the bacterial cell $[68,74]$. 
Bacteria in the biofilm compete with each other due to limited space for growth and the amount of nutrient substrates. Many species evolved their own mechanisms assuring their survival, e.g., the production of bacteriocins, specific or non-specific proteins involved in inter-bacterial interactions [88]. The analysis of the interactions between the physiological flora and cariogenic factors of dental caries was possible due to the studies using double cultures. The control group for double cultures in the study was single cultures of each bacterial species. The results of the experiments are summarized in Table 1.

\begin{tabular}{|c|c|c|c|}
\hline Double culture & $\begin{array}{l}\text { Biofilm growth } \\
\text { and formation }\end{array}$ & Expression of $S$. mutans pathogenicity factors & References \\
\hline \multirow[t]{2}{*}{$\begin{array}{l}\text { S. mutans + } \\
\text { S. gordonii }\end{array}$} & $\begin{array}{l}\text { Decrease in the } \\
\text { growth rate } \\
\text { and biomass }\end{array}$ & $\begin{array}{l}\text { Decrease in expression of genes involved in } \\
\text { the transport and metabolism of carbo } \\
\text { hydrates (e.g., sucrose phosphotransferase), } \\
\text { biosyntheses, and cell division (e.g., sucrose-6- } \\
\text { phosphate hydrolase) }\end{array}$ & {$[118]$} \\
\hline & & $\begin{array}{l}\text { Inactivation of the competence stimulating } \\
\text { peptide (CSP), and in a consequence, a } \\
\text { decrease in the amount of produced bacteriocins }\end{array}$ & [113] \\
\hline $\begin{array}{l}\text { S. mutans }+ \\
\text { S. salivarius }\end{array}$ & $\begin{array}{l}\text { Decreased } \\
\text { biomass in } \\
\text { the biofilm }\end{array}$ & $\begin{array}{l}\text { Inactivation of CSP, a decline in the ability to } \\
\text { produce the biofilm }\end{array}$ & {$[114]$} \\
\hline \multirow[t]{2}{*}{$\begin{array}{l}\text { S. mutans }+ \\
\text { V. parvula }\end{array}$} & $\begin{array}{l}\text { Insignificant } \\
\text { effect on the } \\
\text { growth rate }\end{array}$ & $\begin{array}{l}\text { Decrease in the expression of genes of } \\
\text { malate transport and metabolism (malolactic } \\
\text { fermentation, MLF) }\end{array}$ & {$[118]$} \\
\hline & $\begin{array}{l}\text { Increase in } \\
\text { formed } \\
\text { biofilm } \\
\text { thickness }\end{array}$ & $\begin{array}{l}\text { Spatial biofilm change, resulting in an } \\
\text { increased resistance to antibacterial agents }\end{array}$ & [115] \\
\hline $\begin{array}{l}\text { S. mutans + } \\
\text { Actinomyces } \\
\text { naeslundii }\end{array}$ & $\begin{array}{l}\text { Increase in the } \\
\text { biofilm } \\
\text { thickness }\end{array}$ & $\begin{array}{l}\text { No effect on the amount of produced } \\
\text { bacteriocins }\end{array}$ & {$[113]$} \\
\hline $\begin{array}{l}\text { Actinomyces } \\
\text { naeslundii }\end{array}$ & $\begin{array}{l}\text { biofilm } \\
\text { thickness }\end{array}$ & & \\
\hline $\begin{array}{l}\text { S. mutans }+ \\
\text { S. mitis }\end{array}$ & $\begin{array}{l}\text { Increase in } \\
\text { the biofilm } \\
\text { thickness }\end{array}$ & A larger decrease in the extracellular $\mathrm{pH}$ & {$[116,117]$} \\
\hline
\end{tabular}

Table 1. Results obtained in the experiments using double cultures [112-117] with modification.

Some contradictory relations based on antagonism are observed between the streptococci of oral cavity (Table 1). Species from the group of "mitis", i.e., an important group considered 
as non-cariogenic, have the ability to suppress the growth and development of the cariogenic biofilm with the participation of $S$. mutans species and also cause a decrease in the expression of virulence factors in this microorganism; therefore, the species such as S. gordonii, $S$. oralis, $S$. mitis, and $S$. sanguinis are considered by many researchers as the species promoting the health of oral cavity [71, 93, 118]. Epidemiological studies demonstrated a reverse correlation between these two groups of streptococci: the high number of the species from "mitis" is accompanied by a low percentage of microorganisms from "mutans" group [112]. Competition between these two groups of microorganisms is caused by mutual competition for nutrients and a place to live in the biofilm environment [71, 88]. Microorganisms from "mitis" group produce significant quantities of hydrogen peroxide $\left(\mathrm{H}_{2} \mathrm{O}_{2}\right)$, which inhibits protein glycolysis and synthesis in S. mutans and also causes oxidative damage to DNA and proteins, leading to impaired metabolic processes [119]. Glycolytic enzyme, which is most sensitive to the toxic effects of $\mathrm{H}_{2} \mathrm{O}_{2}$, is glyceraldehyde 3-phosphate dehydrogenase, as well as glucose transport system dependent on the phosphoenolpyruvate (PEP-PTS) [88]. Hydrogen peroxide in $S$. sanguinis and $S$. gordonii species is formed in the reaction catalyzed by pyruvate oxidase, in which, next to $\mathrm{H}_{2} \mathrm{O}_{2}$, also and $\mathrm{CO}_{2}$ and acetyl phosphate are formed from pyruvate $[88,118]$. In turn, $\mathrm{H}_{2} \mathrm{O}_{2}$ production in S. oligofermentas species is mediated by two additional enzymes, lactate oxidase, which converts lactate to pyruvate, and L-amino acid oxidase, which catalyzes the oxidative deamination of L-amino acids [71, 118].

Another example of antagonism between these two groups of streptococci is the ability to inactivate the CSP, which is part of QS mechanism in S. mutans. This mechanism mediates, inter alia, the capability for the biofilm formation and bacteriocin production by S. mutans in response to increasing bacterial density in the biofilm. S. gordonii produces specific serine proteases encoded by gene $s g c$, which are able to inactivate CSP. Wang et al. [113] demonstrated that bacteria lacking gene $s g c$ did not cause CSP inactivation and did not inhibit biofilm formation by $S$. mutans. Also Tamura et al. [114] proved the inhibitory effect of $S$. salivarius on the biofilm formation by S. mutans, which depends on CSP inactivation. In S. mutans, CSP regulates an expression of gene glrA responsible for the morphology of the newly formed biofilm. Causing CSP inactivation, $S$. salivarius causes, as a consequence, a decrease in the expression of gene $g l r A$ and the inhibition of proper biofilm formation. S. sanguinis species can also reduce the amount of mutacins produced by $S$. mutans and show faster growth, thus often gaining an advantage over its competitor. S. mutans grow more slowly in mixed biofilm than in the single-species one $[39,88]$.

S. mutans has its own mechanisms enabling it to compete with other species in the microenvironment of the biofilm. It produces higher amounts of organic acid during carbohydrate metabolism, which causes a decrease in the growth rate of other streptococci [71, 88]. Streptococci from the group of non-mutans have the ability to survive and adapt in low $\mathrm{pH}$ conditions; however, in contrast to $S$. mutans, they are unable to proliferate under conditions of considerable acidity. Therefore, an increase in the count of bacteria from the group of mutans, with concurrent reduction in the number of bacteria from the group of mitis, is observed in the case of frequent drop in $\mathrm{pH}$ that occurs in the oral cavity [120]. In addition, $S$. mutans produces special bacteriocins, called mutacins, which inhibit the growth of other 
bacterial species inhabiting the same ecological niches. Bacteriocins are proteins of an antagonistic effect toward closely related species. S. mutans produces several different mutacins, which belong to the following two groups: lantibiotics and non-lantibiotic bacteriocins. Mutacin IV, belonging to non-lantibiotic bacteriocins, demonstrates an activity against streptococci of the groups of mitis and salivarius observed in the biofilm of dental plaque [121, 122]. Mutacins not only cause the inhibition of the growth of microorganisms present in the biofilm, but they can also participate in the mechanism of genetic competence. S. mutans can obtain DNA from closely related species, including S. gordonii. High level of mutacin IV causes the death of neighboring microorganisms, which, as a consequence, causes the release of DNA into the local environment, which can then be incorporated into the genome of S. mutans [123].

Under in vitro culture conditions, the result of the above interactions between these two groups of streptococci depends on which one of the first will inhabit particular environmental niche. However, under in vivo conditions, both groups can coexist together. This is caused, inter alia, by the presence of other bacterial species in the biofilm $[39,112]$. As demonstrated by Liu et al. [112], the growth and formation of biofilm by S. mutans was significantly inhibited during the double culture with $S$. gordonii. However, after the introduction of third species into the culture, i.e., $V$. parvula, the growth rate was comparable to that observed in a single biofilm of S. mutans. This suggests that $V$. parvula, belonging to the early colonizers in the dental plaque, can affect the mutual competition between $S$. mutans and streptococci from mitis group. Kara et al. [115] have also demonstrated that in the double culture with $V$. parvula, S. mutans exhibits higher resistance to bactericidal agents, e.g., chlorhexidine, increasing thereby its ability to survive in such formed structure.

Another example of a protective effect of one species to another is the ability of Actinomyces naeslundii microorganism to neutralize toxic hydrogen peroxide, protecting other microorganisms from the damaging effect of this metabolite [107]. Relationships between bacteria living in the biofilm of dental plaque are complex and subject to dynamic changes with the changes occurring in the biofilm environment. Interspecies interactions play a significant role in the formation, growth, and maturation and stabilization of the biofilm. In the future, a better understanding of these mechanisms may allow to improve the fight with dental biofilm.

\subsection{Modification of already existing biofilm}

A number of substances demonstrating an effective antibacterial activity and inhibiting the development of biofilm are known today, e.g., chlorhexidine, delmopinol, and phenolic compounds. Unfortunately, most of them cause side effects such as vomiting, diarrhea, addiction, and discoloration of the teeth. Therefore, there is still a search for alternative substances demonstrating antibacterial activity that would be safe for the users [124].

For years, the primary role in the fight against tooth decay is played by calcium phosphate having remineralization properties $[125,126]$. A special calcium-phosphate resin was formed very quickly, whose aim was the gradual release of large amounts of these elements in sites requiring reconstruction. Later, this compound gained the form of nanoparticle composite (nanoparticles of amorphous calcium phosphate, NACP), which also found a wide application in dentistry as its predecessor. The benefits of nanoparticle composite are as follows: better 
mechanical opportunities; increase in ions release in acidic environment, rapid neutralization and increase of low $\mathrm{pH}$ to a safe value $(\mathrm{pH}=6)[125,126]$.

NACP was enriched with compounds of quaternary ammonium salts (QAS) that in addition to the remineralization properties would have antibacterial properties. Special application was found for quaternary ammonium dimethacrylate (QADM). The compound has two active antibacterial domains at its ends, which enhance the desired properties, and, in addition, easily mixes with other dental media $[125,126]$. This modification created a completely new composite, demonstrating a strong antibacterial activity. Its application results in lowered viability of microorganisms, both in the planktonic form and in biofilms (including Streptococcus spp. and Lactobacillus spp.), decreased acidity, and depletion of pathogens' metabolic activity $[125,126]$. The mechanism of that feature is connected with QAS compounds amphiphilicity, which allows entering the reactions interfering cell membrane functions. This process is connected with lipid part of membrane and also affects indirectly in taking part in the transport of substances enzymes activity. QAS influence on lipid membrane alter the bacterial cell metabolism activity. Lethal properties of QAS toward a broad spectrum of microorganisms were also used in antibacterial nanoemulsions. In this case, the salt used was cetylpyridinium chloride (CPC) [127]. An antimicrobial nanoemulsion is a dispersing substance, i.e., water and a lipid substance containing surfactant that forms nano-droplets of the emulsion. It is not toxic to humans or animals; however, it exhibits an antibacterial, antifungal, and antiviral properties. The antibacterial properties of the emulsion result from nano-droplets' effect on bacterial cell membrane destabilizing its lipid integration [127]. CPC is capable of inhibiting bacterial fructosyltransferases, which play an important role in the biofilm formation by microorganisms in the oral cavity. Due to this feature, CPC plays a role of the antimicrobial substance (affecting microorganism cell membrane) inhibiting the development of biofilm. An increase in nanoemulsion's efficiency enriching them with CPC resulted in the extension of their use in products for oral hygiene such as toothpastes, mouthwashes, and dental materials, e.g., varnishes and dental fillings [127].

Among QAS, 12-methacryloyloxydodecylpyridinium bromide (MDPB) also found its application in the fight against tooth decay $[128,129]$. MDPB properties and the possibility of its use attracted the attention of a team of scientists [129]. In their experiments, the authors studied the effect of MDPB on the bacterial flora of the oral cavity, interactions with dental materials, and the possibility of synergistic action of that compound with silver nanoparticles (NAg). MDPB is a monomer demonstrating antibacterial properties with respect to aerobic and anaerobic bacteria isolated from caries lesions (i.e., Actinomyces, S. mutans), as well as antifungal activity (e.g., Candida albicans) [129]. Hardened by the polymerization of binding layer of the filling, it remains active in its against bacteria, concurrently not affecting adversely either the human cells or the binding capacity of the filling material [129].

Silver compounds became the aim of studies conducted by Cheng et al. (2013), who drew the attention to their use combined with QADM. Silver is known for its lethal activity against a wide range of bacteria, viruses, and fungi. Its antibacterial properties are because of the ability of disintegration of microorganism cell membrane, penetration through the membrane, and organelles destruction. Another mechanism causes the bacterial enzymes inactivation 
(inhibits capabilities of bacterial DNA replication). All these pathways increase silver compounds efficacy. The other advantages of these compounds are low toxicity, long-term antibacterial effect (gradual silver release). In the fight against microorganisms significant is lower bacterial resistance to silver compounds than to antibiotics [128-130]. Therefore, many mechanisms and properties that make up the activity of substances containing silver particles cause the inability of formation of the systems of full protection against their effects by microorganisms. An additional difficulty is an activity of silver compounds as catalysts, not as substances incorporating into chemical reactions [131]. Silver nanoparticles have a large active surface, and therefore they represent only 0.05 to $0.1 \%$ wt. of the filling in the dental composites. This amount provides both effective antibacterial activity and no effect on color and mechanical properties of the filling [128].

The study of both teams demonstrated that the combination of NAg with MDPB and Nag with QADM give much better results than the use of these substances alone. It can be noticed as shown in Table 2 that the combination of silver nanoparticles with MDPB and QADM does not affect the mechanical properties of dental material and is not toxic to the cells of the human body. The big advantage of such combinations is an increased ability for inhibiting the growth of microorganisms, as well as a significant reduction in their metabolic activity and vitality.

\begin{tabular}{llll}
\hline Feature & Control & MDPB + & QADM + \\
NAg
\end{tabular}

${ }^{a}$ MTT - tetrazolium dye.

Table 2. An effect of MDPB+NAg and QADM+NAg on the selected features; $[128,129]$ with modification.

Silver also found a combination with fluoride forming silver diamine fluoride (SDF) demonstrating antibacterial properties, which in turn are the result of metal component and remineralization properties due to the presence of fluoride [132]. It was demonstrated that SDF can 
be used as an element in the prevention of caries [133], as well as a substance inhibiting the development of the disease in children, reducing the number of cariogenic microorganisms in oral cavity and corrective action in the sites of tooth enamel demineralization [132]. As described above, the study on the compound also demonstrated the sensitivity of S. mutans and Actinomyces naeslundii to its activity [134]. However, there are the studies verifying SDS effect on two-species bacterial biofilm formed by Streptococcus mutans and Lactobacillus acidophilus. Oral biofilm is not a single species structure, so such studies better illustrate the activity of oral cavity biofilm compound [132]. This is confirmed by the ratio of live to dead cells, which for the control was 0.02 while for the sample containing SDF was 6.74. These studies, in addition to the confirmation of antibacterial SDF activity on S. mutans and L. acidophilus, also proved that the substance slows down the process of enamel demineralization and protects collagen against destruction. This dual activity of SDF can contribute to widen its use in the products for oral cavity hygiene, as well as clinical success in the fight against dental caries.

There is still a search for antibacterial substances that may be included in the formulations for oral cavity hygiene and would not exert adverse effects. One of such substances is chitosana polysaccharide formed as a result of N-acetylation of chitin [135]. Both of these compounds are present in the world of plants, fungi, and animals and demonstrate the natural antibacterial and antifungal properties. However, a limitation of chitosan use in formulations for oral cavity hygiene is its insolubility in water since the compound is soluble only in acids. Attempts aimed to modify that the property, as a result of Millard reaction or sugar modification, caused the formation of chitosan soluble in water with unchanged antibacterial properties. The studies [135] demonstrated that such modified chitosan exhibits the highest antimicrobial activity with respect to microorganism isolated from the oral cavity in an environment of $\mathrm{pH}$ ranges between 5 (for e.g. Staphylococcus aureus, Streptococcus mutans) and 8 (for e.g. Staphylococcus saprophyticus). The optimum temperature in which the antimicrobial activity remained at a level of $50-96 \%$ in relation to the above bacterial species for chitosan activity is $37^{\circ} \mathrm{C}$. The minimum concentration of chitosan inactivate K. pneumoniae, L. brevis and S. saprophyticus was $400 \mu \mathrm{g} / \mathrm{ml}$, while other species need $500 \mu \mathrm{g} / \mathrm{ml}$. It was also found that only $5 \mathrm{~s}$ is sufficient for chitosan to exhibit antimicrobial activity with respect to the microorganisms of the above species at a level of $99.6 \%$ and 20 s caused that this level was $99.9 \%$. It was proved therefore that the water-soluble chitosan demonstrates comparable efficacy in the fight against dental caries like the commonly used antibacterial substances used in the fluids of the oral cavity care. A very strong argument for the use of chitosan in such formulations is also its much lower toxicity than that of the conventionally used alcohols, chlorhexidine, and cetylpyridinium chloride [135], which are commonly used in compositions for oral cavity disinfection in upper respiratory tract diseases, e.g., Tantum Verde.

Another safe, potential solution for humans for the problem of dental plaque is antimicrobial peptides (AMPS). Currently, the information from more than 2600 characterized antimicrobial peptides is available. An ever-increasing number of antimicrobial peptides allowed to create a database gathering all available and characterized antimicrobial peptides (http:// aps.unmc.edu/AP/main.php/). The vast number and variety of AMPs exclude a general 
discussion of this issue. AMPS are alternative to the conventional antibiotic therapy. The works on dozens of antimicrobial peptides that can be used for a more targeted approach associated with selective control or elimination of the strains that cause tooth decay in children have been conducted currently. In addition, their features cause that they are much safer for the youngest users. A number of features of these substances, such as a broad antibacterial spectrum, stability, low toxicity, lack of staining on the teeth, odorless nature, suggest that these compounds should be studied further. Their potential use in the oral therapy should be discussed [124,136].

Within the limitations of the existing data, presented overview of AMPs has been elaborated based on the following features of selected peptides: documented antimicrobial activity with respect to cariogenic microorganisms, broad spectrum of antibacterial activity (gram-positive bacteria and other microorganisms that colonize oral cavity), profitable structural characteristics (i.e., size and conformation), durability (resistance to proteases or other salivary protein activity), and low cytotoxicity (only those peptides for which the data were available) $[137,138]$. The first large group consists of eukaryotic antimicrobial peptides, which include beta defensins of a structure of beta harmonica stabilized by the presence of two or three disulfide bridges, linear peptides that adopt an amphipathic alpha helical structure when associated with the cell membrane lipids, which include magainins, histatins; rope peptides modified by the presence of cysteine binding bridges, such as cathelicidins, peptides with loop structure; and peptides with cyclized peptide chain. One can include those with cationic residues, like histidine, arginine or lysine [137].

A range of histatin derivatives, like its derivative PAC113, demonstrates an increased activity against S. mutans and S. sobrinus [139]. PAC113 found practical application of for the treatment of dental caries. The results of the second phase of the clinical trials using the above discussed derivative of PAC113, in which the children are given lotions and jellies, confirm that the PAC113 is safe and effectively inhibits the growth of fungi and cariogenic bacteria in accordance with its intended purpose, which makes it an ideal candidate for further clinical trials with the indication for caries prevention [137]. A high therapeutic potential was demonstrated for the derivative of histatin 5, called Dhvar1-5, used as a scaffold for the design of analogues of histatin 5. Due to the fact that histatin 5 is a poorly amphipathic peptide, its derivatives Dhvar 1 and 2 are designed to improve amphipathic properties of alpha-helical conformation by the change of histidine to lysine or glutamic acid with lysine at the hydrophobic end. This way, derivatives Dhvar 1 and 2 at higher ionic strength demonstrate lethal concentrations LC50 against $S$. mutans in the range between 15.6 and $16.3 \mu \mathrm{g} / \mathrm{ml}$, compared to the concentration of $200 \mu \mathrm{g} / \mathrm{ml}$ for the natural form of histatin 5 [140]. Competitive derivatives Dhvar 3 and 4, in which glutamic acid replaced lysine, have lower lethal concentrations LC50 against $S$. mutans at a level of 0.7 and $7.6 \mu \mathrm{g} / \mathrm{ml}$. Moreover, the analysis of protein proteolysis during $S$. mutans incubation with the examined derivatives showed no proteolysis fragments, suggesting that the derivatives Dhvar 3 and 4 are resistant to cleavage by the proteases excreted by S. mutans. Also in the case of Dhvar 4, the number of strains of S. mutans, S. sanguinis, and Actinomyces naeslundii in a multi-species bacterial biofilm is decreased by more than $90 \%(100 \mu \mathrm{g} / \mathrm{ml}$ peptide after $30 \mathrm{~min})$. Such a strong antibacterial activity of the dis- 
cussed histatin derivatives, in particular Dhvar4, constitutes a promising tool against caries $[137,141]$.

Another large group is bacteriocins, which owes their name to the organism from which they originate. Based on the structure and composition, they are classified into three groups. Most bacteriocins exhibit a cationic character, but there are neutral and anionic bacteriocins also, which have strong antibacterial properties [142]. Class I bacteriocins include the so-called lantibiotics, thermostable, polycyclic peptides having a molecular weight of less than $5 \mathrm{kDa}$, which contain untypical amino acids in their structure: lanthionine, 3-methylanthionine, dehydroalanin, dehydrobutyric acid. Best known bacteriocin is nisin (derived from Lactococcus lactis) [143]. The main object of interest in the case of nisin is its use in food industry, and also as an antibiotic and a probiotic in a number of infectious diseases. Also there are a large number of patent applications that present the use of nisin as a component of chewing gum with an emphasis on its anticariogenic effects. The studies also prove that the activity of nisin is comparable to the fluorine ions that are used in oral formulations. However, despite the existing scientific evidences, there is a lack of commercial application of nisin against dental caries or other diseases of the oral cavity. The MIC values for nisin at neutral $\mathrm{pH}$ with respect to $S$. mutans and S. sobrinus are in the range between $625-1250$ and $1250-2500 \mu \mathrm{g} / \mathrm{ml}$, respectively, and its stronger activity is demonstrated against Lactobacillus $(39-1250 \mu \mathrm{g} / \mathrm{ml})$. Furthermore, research on the activity of nisin in the saliva suggests that the needed concentrations for the growth inhibition of cariogenic bacteria are lower $(0.1-100 \mu \mathrm{g} / \mathrm{ml})$. In addition, it was found that the presence of dental caries may enhance the antibacterial activity of nisin at acidic $\mathrm{pH}$, assuring its effective mechanism. More importantly, antibacterial activity against bacteria that cause dental caries is maintained particularly at low $\mathrm{pH}$ at the site of cariogenic bacterial action. There are some trials using nisin, by its dilution with saliva [137, 143]. Another quite well-known bacteriocin is poly-lysine, originally isolated from Streptomyces albulus, sold by Japan mainly for food applications. Like nisin, it exhibits a relatively broad spectrum of antimicrobial activity and is also stable over a wide $\mathrm{pH}$ range and is highly soluble in water. The reported MIC values against $S$. mutans for poly-L-lysine are $20 \mu \mathrm{g} / \mathrm{ml}$. Moreover, poly-lysine and nisin exert a synergistic effect with respect to $S$. mutans in partial inhibition. Complete inhibition of the growth of $S$. mutans is observed in the case of combination of 10 and 50 or 5 and $200 \mu \mathrm{g} / \mathrm{ml}$ [144]. Both nisin and poly-lysine seem to have a common mechanism of action on the same species of oral cavity microorganisms, and further research on the application of the above-described peptides may explain the degree of specificity of the synergistic action. The use two or more active substances in combination, considerably better cope with many obstacles, such as salivary proteases. Thus such complexes can provide better effectiveness and reduce the likelihood of resistance development. Commercialization is preferred in this case since the application of lower concentrations of the peptides in the combination will cause their lower cost. Combination therapy using poly-lysine and nisin may have significant anti-caries potential, hence the specificity of above peptides action [137]. The group of bacteriocins also includes mutacins, as the name implies, it is derived from S. mutans, proposed as anticariogenic agents [145]. 
The production of large, active enzymes on an industrial scale can be expensive, and this seems to be reflected in the high cost of the product. On the contrary, antimicrobial peptides are extensively studied and seem to have a great possibility of purposeful treatment of dental caries. The oral cavity, due to the availability, is appropriate for oral therapy involving these antimicrobial peptides. One of these proteins is $\alpha$-helical protein, chrysoidine- 1 -amphipathic. Chrysoidine-1 has a hydrophilic domain at the C-end of polypeptide chain. Electrostatic interactions of chrysoidine-1 with negatively charged phospholipids of bacterial cell membranes cause tight adhesion to microorganisms. It demonstrates a wide demonstrating a broad spectrum of activity against both gram-negative and gram-positive bacteria. The hydrophilic domain penetrates the bacterial membrane structure, forming the numerous pores in it. Changes in the cell shape were first observed by Wang et al. [124] during their studies using chrysoidine- 1 at the concentrations of $2-4 \mathrm{mg} / \mathrm{ml}$ (depending on bacterial species). Thus, chrysoidine- 1 exhibits a strong destructive effect with respect to the lipid components of cell membrane of microorganisms such as S. mutans, S. sanguinis, S. sobrinus, S. gordonii, Actinomyces spp. and Lactobacillus spp., and therefore is able to induce its disintegration and bacterial lysis. This contributes to the reduced viability of these pathogens, both in the planktonic form and grouped in the biofilm. In relation to S. mutans, chrysoidine-1 demonstrates lethal activity after $30 \mathrm{~min}$ using the concentration eightfold higher than the minimal inhibitory concentration (MIC). For comparison, E. faecalis is killed after 5 min and L. fermentis after 60 min using only fourfold MIC. A. viscosus proved to be more resistant than S. mutans. Its eradication required the use of eightfold MIC for $60 \mathrm{~min}$. [124].

Biofilm structure microorganisms demonstrate about 1000 times higher resistance compared to planktonic phase. Therefore, AMPs could be used most effectively in the early stages of biofilm formation. This would prevent its development and colonization of the oral cavity by another pathogen. In the phase of biofilm maturation, AMPs would only slow down the process of cariogenesis [124].

The problem of infectious diseases inevitably involves a growing number of microorganisms resistant to increasingly broader spectrum of antibiotics (multidrug resistance). Therefore, the attention of scientists is increasingly focused on antimicrobial, antifungal, and antiviral substances of natural origin. Such properties are demonstrated by many metabolites of plant origin, such as polyphenols, alkaloids, tannins, terpenoids, steroids, and flavonoids [146,147]. Despite the proved antibacterial activity, these compounds so far are the only additives in formulations intended for oral cavity hygiene.

Most of the above-presented substances found their application in dentistry and are included in the composites and resins for dental fillings, whose properties allow the reduction of biofilm formation on them and reduce the likelihood of repeated episodes of dental caries in the same place. They were introduced to the treatment, since the commonly used methods for developing of tooth occupied by caries usually do not allow for the removal of bacteria from the hard tissues of the tooth. In such situations, it is suggested to use the antimicrobial agents on already developed dentin. These are usually the fillings releasing ions [148] in the form of nanoparticle of dicalcium phosphate anhydrous (DPCA) or tetracalcium phosphate (TTCP), 
often enriched with fluorine [148], or modifications of such filling, e.g., with an addition of QAS and silver nanoparticles [125, 126, 128, 129].

Iodine compounds (potassium iodine or povidone iodine PVP-I) also reduce the incidence of dental caries. Free iodine ions are the active element of PVP-I complex, which consists of iodine and polyvinylpyrrolidone. Iodine, slowly released from the complex, is able to penetrate bacterial membranes and get into the cytosol, where it inactivates the key proteins in cell metabolism, fatty acids, and nucleotides [149]. No side effects such as discoloration of the teeth, tongue, or change of taste were reported [151]. Moreover, the slow release of iodine minimizes its toxic effect for human cells [150], and its short-term use does not damage even irritated oral cavity mucosa. Hosaka et al. [151] examined the antibacterial activity of PVP-I on two microorganisms associated with the diseases. They demonstrated that PVP-I at a concentration of $7 \%$ obtains an activity that allows to kill $100 \%$ microorganisms of $P$. gingivalis species after 3 min of activity, while the same effectiveness with respect to F. nucleatum was already produced by $5 \%$ PVP-I after $30 \mathrm{~s}$. The results obtained for two-species biofilm formed by the examined microorganisms demonstrated that it is two-hundred times more resistant to the action of the examined substance compared to single-species cultures. Despite the activity of 5\% PVP-I already allowing for the killing of biofilm-forming bacteria, unfortunately, it was demonstrated that concentrations of PVP-I used in common mouthwash fluids $(0.23-0.47 \%)$ are not sufficient for a significant decrease of the biofilm-forming ability of $P$. gingivalis and $F$. nucleatum in a time of $30 \mathrm{~s}-1 \mathrm{~min}$, which was defined as an average mouthwash time [151]. It can thus be concluded on the basis of these reports that mixed bacterial biofilm will be much more resistant to PVP-I compared to planktonic cells.

In children with early childhood caries antibacterial activity of PVP-I was also verified for strains of S. mutans. It was concluded that the application of $10 \%$ PVP-I in healthy and cariously damaged teeth every three months for one year significantly reduced the number of these microorganisms in the oral cavity compared to baseline levels [152]. Lower number of cariogenic bacteria may therefore help to reduce the likelihood of caries levels in children. In the research conducted on a group of 127 children it was demonstrated, that combined treatment with 10\%PVP-I and 5\% fluoride varnish reduces the incidence of new caries lesions by $31 \%$ in relation to the application of the varnish alone [133]. An increasing range of substances that protect from the onset of caries, and concurrently not causing side effects, becomes the hope of creating a formulation for oral cavity hygiene allowing for an effective fight with this disease and complete protection of children from the development of the first changes in deciduous teeth.

\section{Dental plague}

Biofilms present in the oral cavity are three-dimensional structures consisting of the bacteria strains anchored to a solid surface, such as tooth enamel, root cement, or dental implant and are embedded in exopolysaccharides matrix [44]. One of the best known and most commonly reported types of biofilm in the human body is a dental plaque [153]. This is an example of 
supragingival plaque, unlike subgingival plague, involved in the pathogenesis of periodontal diseases or gingivitis [154].

More than 1000 different species of bacteria forming plaque have been indentified so far, and more than half of them failed to grow using the classical microbiology methods $[19,71,103$, $155,156]$. In recent studies using advanced methods of identification with molecular biology techniques, a number of species identified in dental plaque biofilm increased to about 1500 species [71], and some researchers estimate that this number may be as high as 10,000 [118]. The studies conducted using molecular biology methods demonstrated five dominant phylum of bacteria in dental plaque: Firmicutes, Actinobacteria, Bacteroidetes, Fusobacteria, and Proteobacteria. They constitute $80-95 \%$ of the oral cavity microflora (Table 3) [93, 118].

\begin{tabular}{|c|c|c|}
\hline Molecular biology technique & $\begin{array}{l}\text { Bacterial microflora compositions } \\
\text { (the most often isolated species) }\end{array}$ & References \\
\hline $\begin{array}{l}\text { 16S rRNA pyrosequencing } \\
\text { and } 16 \mathrm{~S} \text { cDNA analysis }\end{array}$ & $\begin{array}{l}\text { Firmicutes:Streptococcus } \\
\text { Bacteroidetes:Prevotella, Capnocytophaga } \\
\text { Fusobacteria: Leptotrichia, Fusobacterium } \\
\text { Actinobacteria: Actinomyces, Corynebacterium } \\
\text { Proteobacteria:Camphylobacter }\end{array}$ & [157] \\
\hline $\begin{array}{l}\text { 16S rRNA pyrosequencing } \\
\text { and } 16 \mathrm{~S} \text { cDNA analysis }\end{array}$ & $\begin{array}{l}\text { Firmicutes: Streptococcus, Gemella, Paenibacillus, } \\
\text { Veillonella } \\
\text { Actinobacteria:, Actinomyces, Rothia, Angustibacter, Kineococcus } \\
\text { Proteobacteria: Neisseria, Kingella, Alysella } \\
\text { Bacteroidetes:Capnocytophaga } \\
\text { Fusobacteria: Fusobacterium }\end{array}$ & [158] \\
\hline $\begin{array}{l}\text { 16S rRNA pyrosequencing } \\
\text { and } 16 \mathrm{~S} \text { rDNA analysis }\end{array}$ & $\begin{array}{l}\text { Firmicutes:Streptococcus, Veillonella, Lactobacillus } \\
\text { Proteobacteria:Neisseria, Kingella, Derxia } \\
\text { Actinobacteria:Actinomyces, Corynebacterium } \\
\text { Bacteroidetes:Prevotella, Capnocytophaga } \\
\text { Fusobacteria:Leptotrichia }\end{array}$ & [159] \\
\hline $\begin{array}{l}\text { 16S rRNA pyrosequencing } \\
\text { and 16S rRNA hybridisation } \\
\text { (Human Oral Microbe Identification } \\
\text { Microarray, HOMIM) }\end{array}$ & $\begin{array}{l}\text { Firmicutes:Streptococcus, Veilonella, Granulicatella, } \\
\text { Gemella, Abiotrophia, Selenomonas } \\
\text { Proteobacteria:Neiserria, Camphylobacter } \\
\text { Bacteroidetes:Capnocytophaga } \\
\text { Fusobacteria:Fusobacterium }\end{array}$ & {$[71,93]$} \\
\hline $\begin{array}{l}\text { 16S rRNA of V5-V6 region } \\
\text { pyrosequencing and } 16 \mathrm{~S} \\
\text { cDNA analysis }\end{array}$ & $\begin{array}{l}\text { Firmicutes:Streptococcus, Veillonella, Granulicatella } \\
\text { Proteobacteria:Neisseria, Haemophilus } \\
\text { Actinobacteria:Actinomyces, Corynebacterium, } \\
\text { Rothia } \\
\text { Bacteroidetes:Capnocytophaga, Prevotella, } \\
\text { Porphyromonas } \\
\text { Fusobacteria:Fusobacterium }\end{array}$ & {$[160]$} \\
\hline
\end{tabular}




\begin{tabular}{lll}
\hline Molecular biology technique & $\begin{array}{l}\text { Bacterial microflora compositions } \\
\text { (the most often isolated species) }\end{array}$ & $\begin{array}{c}\text { References } \\
\text { 16S rRNA pyrosequencing }\end{array}$ \\
and 16S cDNA analysis & Firmicutes:Streptococcus, Veillonella & {$[161]$} \\
& Actinobacteria:Corynebacterium, Actinomyces, \\
& Rothia & \\
& Fusobacteria:Fusobacterium, Leptotrichia \\
& Bacteroidetes:Prevotella, Capnocytophaga \\
& Proteobacteria:Neisseria, Haemophilus, Camphylobacter \\
\hline
\end{tabular}

Table 3. Composition of dental plague microflora.

In the studies conducted using the latest methods of molecular biology, the largest group of microorganisms are the bacteria belonging to the Firmicutes phylum. The second place is occupied by bacteria belonging to the Proteobacteria phylum, further Actinobacteria, Bacteroidetes, and Fusobacteria. Many studies confirmed the dominant share of Streptococcus genus, which constitutes more than half of all bacteria in dental plaque biofilms [71, 93, 118, 155, 157, 158]. Another position in this ranking is occupied by bacteria of the genus Veilonella, Granulicatella, Fusobacterium, Neisseria, Actinomyces, Capnocythophaga, Kingella, Camphylobacter, Gemella, Haemophilus, and Prevotella.

Plaque-forming microorganisms can be divided into the so-called early and late colonizers, forming early and late biofilm, respectively. The species of the early colonizers include streptococci, as well as bacteria of the genus Veillonella, Haemophilus, Propionibacterium, Capnocytophaga, Prevotella, Eikenella, or Actinomyces [107]. Late colonizers are microorganisms of the genera Eubacterium, Treponema, and Porphyromonas gingivalis, Aggregatibacter actinomycetemcomitans, Fusobacterium nucleatum, and Prevotella intermedia [107]. As the biofilm matures, the domination of bacteria is transferred from one group to another. Streptococci give way to genera such as Actinomyces, Fusobacterium, or Veillonella [107]. The entire flora of dental plaque was considered for many years as the etiological factor of caries formation (nonspecific plague theory), or only specific microorganisms were considered as pathogenic (specific plague theory). Currently, the main hypothesis of dental caries formation is the so-called ecological plaque hypothesis [162]. The ecological plaque hypothesis combines elements of nonspecific plaque theory and specific plaque theory of caries formation. This theory assumes that changes occurring in the oral environment initiate the changes in the balance of bacterial flora, resulting in the development of more cariogenic species, and are responsible for enamel demineralization over the remineralization. Carbohydrates from the diet are considered to be the most important factor responsible for biochemical and physiological changes observed in the biofilm. Consumption of sugar causes a rapid $\mathrm{pH}$ decrease in the dental plaque. In addition, frequent consumption of carbohydrates increases the percentage of streptococcus from Mutans group, and bacteria from of the Lactobacillus genus, as well as reduces the number of streptococci from mitis group, including S. sanguinis. This is caused by a decrease in the $\mathrm{pH}$ of oral cavity, which is accompanied by carbohydrates metabolism and organic acid production (Figure 4). Additionally, frequent consumption of sucrose promotes tooth decay not only through the acidification of the environment but also by the production 
of extracellular exopolysaccharides (EPS) forming a biofilm matrix (Figure 5). All these processes contribute to an increased risk of dental caries development [62].

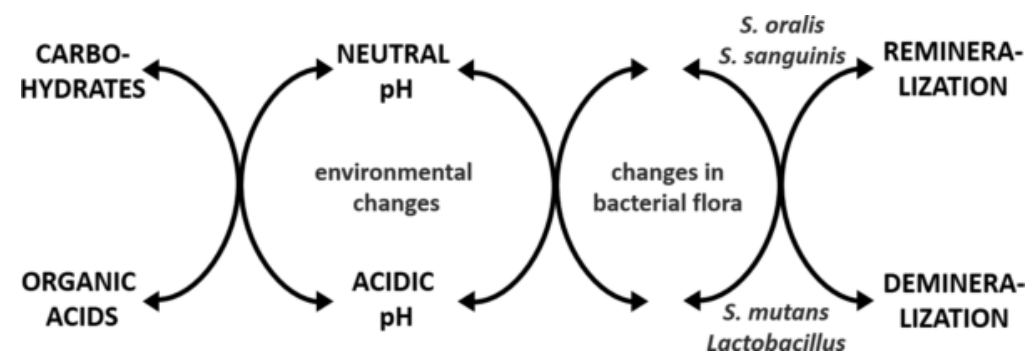

Figure 4. The ecological plaque hypothesis - effect of fermentable carbohydrates on caries development (based on Paes Leme et al. [62]).

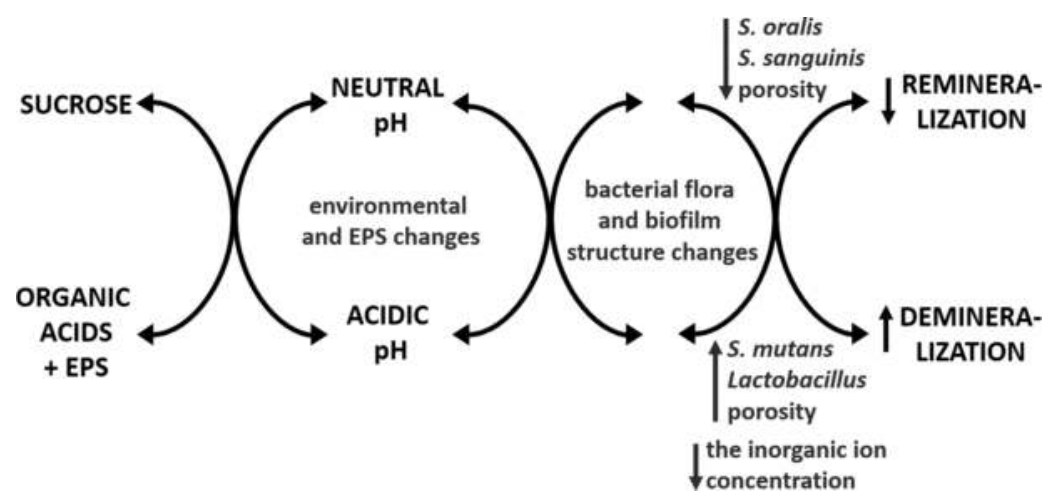

Figure 5. Sucrose effect on caries development (based on Paes Leme et al. [62]).

The species involved in the cariogenic process include Streptococcus sobrinus, Lactobacillus acidophilus, Actinomyces viscosus, and S. mutans species which is the most known and widespread 129]. However, studies indicate that the induction of carious lesions on the dental plaque can occur even in the absence of $S$. mutans [163]. The factors initiating the formation of the above lesions are acidity and acidophilic bacteria other than $S$. mutans [164, 165]. Except the species mentioned above, some authors have also classified Actinomyces naeslundii, Aggregatibacter actinomycetemcomitans, Fusobacterium nucleatum, Prevotella intermedia, and Porphyromonas gingivalis as caries-forming species [166], as well as bacteria of the genera Bifidobacterium or Selenomonas [71].

The six types of bacteria, that is, Streptococcus, Veillonella, Actinomyces, Granulicatella, Leptotrichia, and Thiomonas demonstrate a large differentiation between the dental plaques with active caries and caries without lesions [15]. Studies showed that three types of bacteria, including Streptococcus, Granulicatella, and Actinomyces, occurred predominantly in patients with severe 
forms of caries. In control (free of caries) noted predominant numbers of the Aestuariimicrobium genus [167]. Microbiome of bacteria associated with the formation of dental caries is much more differentiated than previously believed [168].

The microflora of oral cavity demonstrates specificity depending on the stages of caries progression [169]. The study conducted by Gomar-Vercher et al. in 2014 on saliva samples of children with caries showed that the dominant caries-forming species found were bacteria classified to genera Porphyromonas and Prevotella [169]. Using pyrosequencing techniques, attention was paid to species variability on the dental plaque depending on the activity of caries process - in the case of intact plaque, in the presence of the so-called white spots, in the case of damage to the dentin. Diversity of dental plaque microflora of healthy individuals exhibits a much more homogeneity compared to the plague of individuals with caries. Thirteen bacteria of genera Capnocytophaga, Fusobacterium, Porphyromonas, Abiotrophia, Comamonas, Tannerella, Eikenella, Paludibacter, Treponema, Actinobaculum, Stenotrophomonas, Aestuariimicrobium, and Peptococcus were associated with healthy teeth. Eight bacteria of genera Cryptobacterium, Lactobacillus, Olsenella, Megasphaera, Scardovia, Shuttleworthia, Cryptobacterium, and Streptococcus increased significantly in dentine damage, while Actinomyces and Corynebacterium were present predominantly in the so-called "white spots" and Flavobacterium, Neisseria, Bergeyella, and Derxia were numerous with intact dental plaque of individuals with caries [159]. In case of damaged dentin, the study by Obata et al. reported a relatively high percentage of bacteria of the genus Atopobium, Prevotella, or Propionibacterium along with Streptococcus or Actinomyces [170].

However, taking into account the complexity of microorganism-microorganism interactions and the number of microorganisms, which is essential for the formation of biofilm and creation of specific conditions for caries development, it can be concluded that particular species of bacteria acts as the forefront of cariogenic factors [71, 164]. An increasing attention is paid to the study of relations between the course of biofilm formation and its maturation, development of resistance to increased spectrum antibiotics, analysis of microorganisms genome, and mechanisms of action of specific bacterial proteins [171-173]. Considerable focus is also on the structure of biofilm and its relationship with the species forming the microbiota of human oral cavity.

\section{Role of oral microbiome in the formation of dental plaque}

The knowledge of the microbial diversity in human oral cavity has recently been improved and was subjected to a considerable transformation in the last two decades. Understanding biological characteristics and functions of individual bacterial species colonizing oral cavity, which are subject to dynamic changes, has become the fundamental objective of studies on human microbiome. The function of the oral microbiome can be determined on the basis of characteristics of microbes isolated in vitro. Currently, no efficient referential method exists for the evaluation of the actual presence of bacteria in the oral cavity. The culture methods carry their limitations related to the lack of ensuring all the necessary growth conditions for each of 
the microbiota species under in vitro conditions. Both the interpretation of culture results and molecular tests pose numerous problems, in particular, due to the fact that the mere presence of an occasional isolation or determination of bacterial DNA does not mean that a given species colonizes the oral cavity and its individual anatomical areas-it can occur there temporarily. Bacteria in the oral cavity can (which we discussed in subchapter) occur accidentally as a result of age-dependent transformation, coming through primary teeth, their extractions, carious lesions, dentures, restorations, edentulism, and also temporary changes, which can be induced by diet, variable saliva flow, or lasting antibiotic treatment. Environmental conditions, such as temperature, salinity, availability of oxygen and nutrients, variable $\mathrm{pH}$ conditions, and redox, may have an effect on the ecosystem and contribute to the modification of the species composition of biofilms found on every location.

This is corroborated by taxonomic studies comparing bacterial species composition of the oral microbiome with species forming the dental plaque, and in these studies, more attention was paid to the occurrence of species diversity, however, with a very similar metabolic activity characteristic of individual representatives of the oral microbiome and the dental plaque [155]. The presented data suggest that modifications in the taxon proportions occur between the oral microbiome and biofilm. However, it is important to note that these constitute changes caused by the functional abilities of certain taxonomic groups (induced by their metabolic activity, i.e., the use of carbohydrates and tolerance to low $\mathrm{pH}$ ). Populations of microorganisms exhibit similar stability, which enables us to gather the basic knowledge on the behavior of the abovementioned microbes under in vivo conditions.

As a result of the evaluation of phylogenetic relationship of bacteria found in saliva samples of healthy persons and bacteria forming the biofilm model imitating the dental plaque in vivo, attention was paid to the occurrence of affinities between species, in particular, within the Streptococcus genus and to a lesser degree in Veillonella (Figure 6) [2, 4, 155, 174]. In the case of the Streptococcus genus, the most dominant units within the human oral taxa (HOT) were $S$. vestibularis, S. salivarius, S. mitis, S. parasanguinis, and different undiscovered Streptococcus spp. The strains of $S$. vestibularis constituted approximately $40 \%$ of the total biofilm microbes, whereas S. salivarius (HOT-755) and various other undiscovered Streptococcus sp. (HOT-C65) each occupied $10 \%$. S. vestibularis is the representative of physiological flora of the oral cavity, and its presence is uncommonly associated with the disease, except for few cases of infectious endocarditis, neonatal sepsis, bacteraemia, and in patients with cancer [175]. Furthermore, a few studies demonstrated that $S$. vestibularis may be the etiological factor of caries in rats, compared to other Streptococcus species (e.g., S. salivarius), which are associated with the development of the disease much more commonly [176]. S. salivarius, which has extensive functions from being highly cariogenic [177] to the protective function against caries development (i.e., through hydrolysis of urea to ammonia [178], influences the health state of the human oral cavity. The strains of S. parasanguinis (HOT-721 and HOT-711) constituted a considerable participation $(10 \%)$ in the presented in vitro biofilm model. The role of $S$. parasanguinis in the health of oral cavity is poorly known. Due to the ability of this microorganism for carbohydrate fermentation to lactate and other organic acids, S. parasanguinis is considered to be an organism with moderate tolerance to low $\mathrm{pH}$ and a low cariogenic 
species $[179,180]$. The previous studies suggested that these bacteria were significantly related to both caries in small children and the physiological flora of the oral cavity [181, 182]. This fact is not confirmed by recent study Krzyściak et al.'s [183] in which, apart from a detailed description of $S$. mutans, constituting $24 \%$ of natural physiological flora of children without symptoms of the caries disease and $77 \%$ of cariogenic flora in children with early childhood caries (ECC), presence of $S$. parasanguinis constituted only $2 \%$.

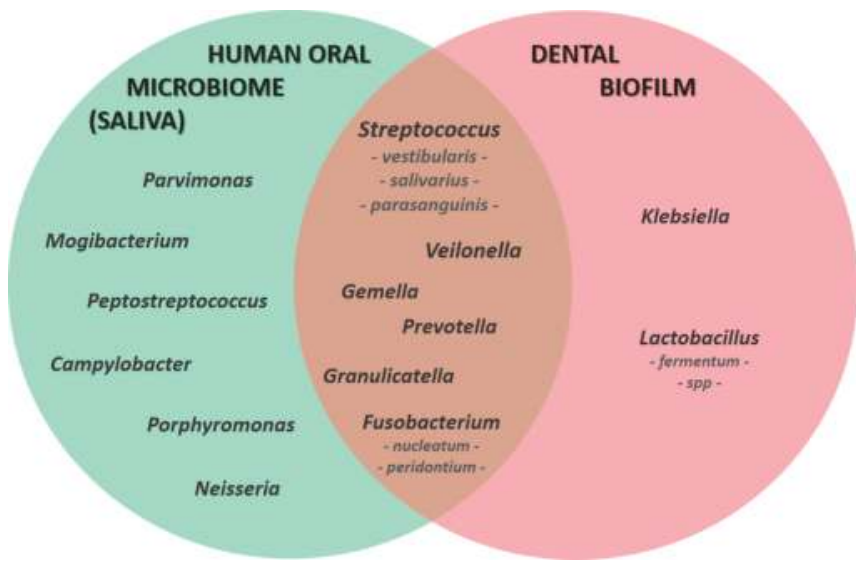

Figure 6. Results of phylogenetic relationship evaluation of bacteria found in saliva samples (oral microbiome) of healthy persons and bacteria forming the biofilm model imitating in vivo dental plaque.

The presence of $S$. mutans bacteria onto the teeth surfaces is usually related to poor hygiene and diet. These bacteria dwell in the oral cavity, occupying hard tissues; but they also colonize soft tissues from which they can be easily transferred to the oral cavity, in particular, with shared use of personal care products or during kissing. It appears also that maintaining the oral cavity in the state of lowered moisture (frequent snacking) may favor colonization and the resulting infection. It is possible that irrigation itself, without the use of disinfectants, may also constitute the source of colonization [157, 184].

The presence of the Veillonella genus in the presented biofilm model and saliva samples creates new opportunities related to the role of this genus in the interspecific relations between the oral microbiome and caries development. In earlier studies, the role of Veillonella remained unexplained, and all the available laboratory tests demonstrated that the growth effects of microbes of the Veillonella genus can be mixed [185, 186]. It is also suggested that the presence of the Veillonella genus can be used for forecasting the possibility of caries development in children without symptoms of the disease due to its close relationship with $S$. mutans, which was identified in all samples of the above study (HOT-686) [187].

On the contrary, the lactic acid bacteria of the Lactobacillus genus were identified in the few samples obtained from the supragingival area of healthy persons. The representatives of this genus are considered to be late colonizers [2]; they commonly occur in advanced caries (low 
$\mathrm{pH}$ [22]. Two Lactobacillus species (L. fermentum HOT-608 and Lactobacillus sp. HOT-A89) were identified in the presented model with a relatively low growth $(\bar{X}=0.8 \%)$. This means that the opportunity to alter the view on the participation of this genus is only as normal physiological flora exhibiting an increased possibility to cause the disease as a result of the movement of this genus from the physiological flora to the disease conditions [155, 188].

Interestingly, Fusobacterium genus, which appears to play a less significant role in the oral microbiome in children, similar to the TM7 strain [14], constituted approximately $10 \%$ of the total diversity of microbial genes forming the presented biofilm model. Similar to the majority of other microbes, microorganisms belonging to the Fusobacterium genus are known not only as the normal physiological flora of the oral cavity, but also as the flora responsible for causing the diseases of oral cavity under special conditions [189]. Their ability to grow in different environments can be explained by their universal metabolism, which enables them to obtain energy from fermentation of simple sugars, simple and branch-chained amino acids [189].

Many bacteria of the oral microbiome, including species forming the dental plaque, are opportunistic species (until recently considered to be non-pathogenic), and due to this fact, their appearance in sites normally unavailable to them in the case of habitat disturbance (disturbance of the immune system functioning of the host) may initiate the development of infection. This is corroborated by the results described above, indicating an increased frequency of the occurrence of the bacteria of physiological flora in the dental plaque, which are exposed not only to the changes in the oxidation-reduction potential, local $\mathrm{pH}$, but also in the response to diet and all types of environmental conditions constituting the source or nourishment for bacteria. In children, studies on the oral microbiome independent of cultures demonstrated that apart from the DNA of Streptococcus, Veillonella, Lactobacillus and Granulicatella, Rothia and Actinomyces, the most common type of DNA belonged to Bacteroidales and Prevotella, and also Fusobacterium, Spirochaetes, and the TM7 strain [14]. Streptococcus, and to a lesser degree Veillonella, also dominated in the studies evaluating phylogenetic relationships of bacteria forming the dental plaque with the oral microbiome species $[155,190]$.

\section{Conclusion}

As it was mentioned earlier, only approximately $40 \%$ of the oral microbiome bacteria are cultured in vitro. Due to this fact, studies on the function of non-cultured bacteria should be carried out using other methods, and thus looking for such a solution that enables understanding their properties without the need for in vitro isolation. Such possibilities are provided by metagenomics, which studies sequences of DNA obtained directly from the environment of the oral cavity, treated as one common gene set [191]. An oral microbiome analysis depending on the genotypic characteristics of the host, as well as its metabolic phenotype, will allow us to understand all these factors which responsible for maintaining host- microbiota homeostasis. The formation of genetic maps (including host, as well as microbiota) of such environments and the detection of biofactors indicating the predisposition for a given disease may contribute to the development of new diagnostic methods in reference to individual 
persons, and thus individualized therapy. So far, numerous active bacterial factors and molecular mechanisms of their interactions with the host have been discovered. However, the problem of the presence of healthy oral microbiome bacteria and relating teeth colonization with a potential infection development requires further study.

\section{Author details}

Wirginia Krzyściak ${ }^{1 *}$, Anna Jurczak ${ }^{2}$ and Jakub Piątkowski ${ }^{3}$

*Address all correspondence to: wirginiakrzysciak@cm-uj.krakow.pl

1 Department of Medical Diagnostics, Pharmacy Faculty, Medical College, Jagiellonian University, Krakow, Poland

2 Department of Pediatric Dentistry, Institute of Dentistry, Medical College, Jagiellonian University, Krakow, Poland

3 Genetics Laboratory, Department of Endocrinology, Medical College, Jagiellonian University, Krakow, Poland

\section{References}

[1] Dewhirst FE, Chen T, Izard J, Paster BJ, Tanner AC, Yu WH, Lakshmanan A, Wade WG. The human oral microbiome. J Bacteriol. 2010;192:5002-5017. DOI: 10.1128/JB. 00542-10.

[2] Human Microbiome Project Consortium. Structure, function and diversity of the healthy human microbiome. Nature. 2012;486:207-214.

[3] Sheiham A. Dietary effects on dental diseases. Public Health Nutr. 2001;4:569-591.

[4] Nasidze I, Li J, Quinque D, Tang K, Stoneking M. Global diversity in the human salivary microbiome. Genome Res. 2009;19:636-643. DOI: 10.1101/gr.084616.108.

[5] Takahashi N, Nyvad B. The role of bacteria in the caries process: ecological perspectives. J Dent Res. 2011;90:294-303. DOI: 10.1177/0022034510379602.

[6] Sampaio-Maia B, Monteiro-Silva F. Acquisition and maturation of oral microbiome throughout childhood: An update. Dent Res J (Isfahan). 2014;11:291-301.

[7] Dominguez-Bello MG, Costello EK, Contreras M, Magris M, Hidalgo G, Fierer N, Knight R. Delivery mode shapes the acquisition and structure of the initial microbiota across multiple body habitats in newborns. Proc Natl Acad Sci USA. 2010;107:1197111975. 
[8] Bagg J, MacFarlane TW, Poxton IR, Smith AJ. Essentials of Microbiology for Dental Students. New York: Oxford University Press. 2006;237-258.

[9] Hegde S, Munshi AK. Influence of the maternal vaginal microbiota on the oral microbiota of the newborn. J Clin Pediatr Dent. 1998;22:317-321.

[10] Twetman S, García-Godoy F, Goepferd SJ. Infant oral health. Dental Clin North Am. 2000;44:487-492.

[11] Cephas KD, Kim J, Mathai RA, Barry KA, Dowd SE, Meline BS, Swanson KS. Comparative analysis of salivary bacterial microbiome diversity in edentulous infants and their mothers or primary care givers using pyrosequencing. PLoS One. 2011;6:e23503. DOI: 10.1371/journal.pone.0023503.

[12] Cole MF, Evans M, Fitzsimmons S, Johnson J, Pearce C, Sheridan MJ, Wientzen R, Bowden G. Pioneer oral streptococci produce immunoglobulin A1 protease. Infect Immun. 1994;62:2165-2168.

[13] Caufield PW, Cutter GR, Dasanayake AP. Initial acquisition of mutans streptococci by infants: evidence for a discrete window of infectivity. J Dent Res. 1993;72(1):37-45.

[14] Crielaard W, Zaura E, Schuller AA, Huse SM, Montijn RC, and Keijser BJ. Exploring the oral microbiota of children at various developmental stages of their dentition in the relation to their oral health. BMC Med Genomics. 2011;4:22. DOI: 10.1186/1755-8794-4-22

[15] Ling Z, Kong J, Jia P, Wei C, Wang Y, Pan Z, Huang W, Li L, Chen H, Xiang C. Analysis of oral microbiota in children with dental caries by PCR-DGGE and barcoded pyrosequencing. Microb Ecol. 2010;60:677-690. DOI:10.1007/s00248-010-9712-8

[16] Gizani S, Papaioannou W, Haffajee AD, Kavvadia K, Quirynen M, Papagiannoulis L. Distribution of selected cariogenic bacteria in five different intra-oral habitats in young children. Int J Paediatr Dent. 2009;19:193-200. DOI: 10.1111/j.1365-263X.2008.00956.x.

[17] Tanner AC, Mathney JM, Kent RL, Chalmers NI, Hughes CV, Loo CY, Pradhan N, Kanasi E, Hwang J, Dahlan MA, Papadopolou E, Dewhirst FE. Cultivable anaerobic microbiota of severe early childhood caries. J Clin Microbiol. 2011;49(4):1464-1474. DOI: 10.1128/JCM.02427-10.

[18] Jurczak A, Kościelniak D, Papież M, Vyhouskaya P, Krzyściak W. A study on $\beta$ defensin-2 and histatin-5 as a diagnostic marker of early childhood caries progression. Biol Res. 2015;31:48-61. DOI: 10.1186/s40659-015-0050-7.

[19] Aas JA, Griffen AL, Dardis SR, Lee AM, Olsen I, Dewhirst FE, Leys EJ, Paster BJ. Bacteria of dental caries in primary and permanent teeth in children and young adults. J Clin Microbiol. 2008;46:1407-1417.

[20] Van Houte J, Lopman J, Kent R. The predominant cultivable flora of sound and carious human root surfaces. J Dent Res. 1994;73(11):1727-1734. 
[21] Van Houte J, Sansone C, Joshipura K, Kent R. Mutans streptococci and non-mutans streptococci acidogenic at low $\mathrm{pH}$, and in vitro acidogenic potential of dental plaque in two different areas of the human dentition. J Dent Res. 1991;70:1503-1507.

[22] Gross EL, Leys EJ, Gasparovich SR, Firestone ND, Schwartzbaum JA, Janies DA, Asnani K, Griffen AL. Bacterial 16S sequence analysis of severe caries in young permanent teeth. J Clin Microbiol. 2010;48:4121-4128. DOI: 10.1128/JCM.01232-10.

[23] Tanner AC, Milgrom PM, Kent R Jr, Mokeem SA, Page RC, Liao SI, Riedy CA, Bruss JB. Similarity of the oral microbiota of pre-school children with that of their caregivers in a population-based study. Oral Microbiol Immunol. 2002;17:379-387.

[24] Mombelli A, Gusberti FA, van Oosten MA, Lang NP. Gingival health and gingivitis development during puberty. A 4-year longitudinal study. J Clin Periodontol. 1989;16:451-456.

[25] Krzyściak W, Jurczak A, Piątkowski J, Kościelniak D, Gregorczyk-Maga I, Kołodziej I, Papież MA, Olczak-Kowalczyk D. Effect of histatin-5 and lysozyme on the ability of Streptococcus mutans to form biofilms in in vitro conditions. Postepy Hig Med Dosw (Online). 2015;69:1056-1066.

[26] Krzyściak W, Jurczak A, Kościelniak D, Bystrowska B, Skalniak A. The virulence of Streptococcus mutans and the ability to form biofilms. Eur J Clin Microbiol Infect Dis. 2014;33:499-515. DOI: 10.1007/s10096-013-1993-7.

[27] Report WHO. Weekly Epidemiological Record (WER) 2016;91:21-32.

[28] Nakano K, Inaba H, Nomura R, Nemoto H, Takeda M, Yoshioka H, Matsue H, Takahashi T, Taniguchi K, Amano A, Ooshima T. Detection of cariogenic Streptococcus mutans in extirpated heart valve and atheromatous plaque specimens. J Clin Microbiol. 2006;44:3313-3317.

[29] Delorme C, Poyart C, Ehrlich SD, Renault P. Extent of horizontal gene transfer in evolution of Streptococci of the salivarius group. J Bacteriol. 2007;189:1330-1341.

[30] Kilian M, Poulsen K, Blomqvist T, Håvarstein LS, Bek-Thomsen M, Tettelin H, Sørensen UB. Evolution of Streptococcus pneumoniae and its close commensal relatives. PLoS One. 2008;3:2683. DOI: 10.1371/journal.pone.0002683.

[31] Fitzgerald JR, Musser JM. Evolutionary genomics of pathogenic bacteria. Trends Microbiol. 2001;9:547-553.

[32] Sørensen UB, Poulsen K, Ghezzo C, Margarit I, Kilian M. (2010) Emergence and global dissemination of host-specific Streptococcus agalactiae clones. MBio. 2010;1:e00178-10. DOI: $10.1128 / \mathrm{mBio} .00178-10$.

[33] Henderson B, Poole S, Wilson M. Bacterial modulins: a novel class of virulence factors which cause host tissue pathology by inducing cytokine synthesis. Microbiol Rev. 1996;60:316-341. 
[34] Casadevall A, Pirofski LA. Host-pathogen interactions: redefining the basic concepts of virulence and pathogenicity. Infect Immun. 1999;67:3703-3713.

[35] Kreikemeyer B, Gámez G, Margarit I, Giard JC, Hammerschmidt S, Hartke A, Podbielski A. Genomic organization, structure, regulation and pathogenic role of pilus constituents in major pathogenic Streptococci and Enterococci. Int J Med Microbiol. 2011;301:240-251.

[36] Bagnoli F, Moschioni M, Donati C, Dimitrovska V, Ferlenghi I, Facciotti C, Muzzi A, Giusti F, Emolo C, Sinisi A, Hilleringmann M, Pansegrau W, Censini S, Rappuoli R, Covacci A, Masignani V, Barocchi MA. A second pilus type in Streptococcus pneumoniae is prevalent in emerging serotypes and mediates adhesion to host cells. J Bacteriol. 2008;190:5480-5492.

[37] Casadevall A, Fang FC, Pirofski LA. Microbial virulence as an emergent property: consequences and opportunities. PLoS Pathog. 2011 Jul;7(7):e1002136. doi: 10.1371/ journal.ppat.1002136. Epub 2011 Jul 21.

[38] Ahn SJ, Ahn SJ, Wen ZT, Brady LJ, Burne RA. Characteristics of biofilm formation by Streptococcus mutans in presence of saliva. Infect Immun. 2008;76:4259-4268.

[39] Wen ZT, Yates D, Ahn SJ, Burne RA. Biofilm formation and virulence expression by Streptococcus mutans are altered when grown in dual-species model. BMC Microbiology, 2010;10:111-119.

[40] Khan AU, Islam B, Khan SN, Akram M. A proteomic approach for exploring biofilm In Streptococcus mutans. Bioinformation. 2011;5:440-445.

[41] Socransky SS, Haffajee AD. Dental biofilms: difficult therapeutic targets. Periodontol 2000. 2002;28:12-55.

[42] Matsui R, Ccitkovitch D. Acid tolerance mechanisms utilized by Streptococcus mutans. Future Microbiol. 2010;5:403-417.

[43] Banas JA. Virulence properties of Streptococcus mutans. Front Biosci. 2004;1:1267-1277.

[44] Zijnge V, van Leeuwen MB, Degener JE, Abbas F, Thurnheer T, Gmür R, Harmsen HJ. Oral biofilm architecture on natural teeth. PLoS ONE. 2010;5:e9321.

[45] Kolenbrander PE, Palmer RJ Jr, Rickard AH, Jakubovics NS, Chalmers NI, Diaz PI. Bacterial interactions and successions during plaque development. Periodontol 2000. 2006;42:47-79.

[46] Rickard AH, Gilbert P, High NJ, Kolenbrander PE, Handley PS. Bacterial coaggregation: an integral process in the development of multi-species biofilms. TRENDS in Microbiology, 2003;11:94-100.

[47] Huang L, Xu QA, Liu C, Fan MW, Li YH. Anti-caries DNA vaccine-induced secretory immunoglobulin A antibodies inhibit formation of Streptococcus mutans biofilms in vitro. Acta Pharmacol Sin. 2013;34:239-246. 
[48] Klein MI, Xiao J, Lu B, Delahunty CM, Yates JR 3 ${ }^{\text {rd }}$, Koo H. Streptococcus mutans protein synthesis during mixed-species biofilm development by kigh-throughput quantitative proteomics. PLoS ONE. 2012;7:e45795.

[49] Postollec F, Norde W, de Vries J, Busscher HJ, van der Mei HC. Interactive forces between co-aggregating and non-co-aggregating oral bacterial pairs. J Dent Res. 2006;85:231-234.

[50] Franková J, Pivodová V, Růžička F, Tománková K, Šafářová K, Vrbková J, Ulrichová J. Comparing biocompatibility of gingival fibroblasts and bacterial strains on a different modified titanium discs. J Biomed Mater Res A. 2013;101:2915-2924. DOI: 10.1002/ jbm.a.34598.

[51] Signoretto C, Marchi A, Bertoncelli A, Burlacchini G, Milli A, Tessarolo F, Caola I, Papetti A, Pruzzo C, Zaura E, Lingström P, Ofek I, Spratt DA, Pratten J, Wilson M, Canepari P. Effects of mushroom and chicory extracts on the shape, physiology and proteome of the cariogenic bacterium Streptococcus mutans. BMC Complement Altern Med. 2013;13:117. DOI: 10.1186/1472-6882-13-117.

[52] Soell M, Hemmerlé J, Hannig M, Haïkel Y, Sano H, Selimovic D. Molecular force probe measurement of antigen I/II-matrix protein interactions. Eur J Oral Sci. 2010;118:590 595. DOI: 10.1111/j.1600-0722.2010.00785.x.

[53] Compagnoni MA, Pero AC, Ramos SM, Marra J, Paleari AG, Rodriguez LS. Antimicrobial activity and surface properties of an acrylic resin containing a biocide polymer. Gerodontology. 2014;31:220-226. DOI: 10.1111/ger.12031.

[54] Busscher HJ, van Hoogmoed CG, Geertsema-Doornbusch GI, van der Kuijl-Booij M, van der Mei HC. Streptococcus thermophilus and its biosurfactants inhibit adhesion by Candida spp. on silicone rubber. Appl Environ Microbiol. 1997;63:3810-3817.

[55] Bowen WH, Koo H. Biology of Streptococcus mutans-derived glucosyltransferases: role in extracellular matrix formation of cariogenic biofilms. Caries Res. 2011;45:69-86.

[56] Siqueira WL, Bakkal M, Xiao Y, Sutton JN, Mendes FM. Quantitative proteomic analysis of the effect of fluoride on the acquired enamel pellicle. PLoS ONE. 2012;7:e42204.

[57] Brady LJ, Maddocks SE, Larson MR, Forsgren N, Persson K, Deivanayagam CC, Jenkinson HF. The changing faces of Streptococcus antigen I/II polypeptide family adhesins. Mol Microbiol. 2010;77:276-286.

[58] Esberg A, Löfgren-Burström A, Ohman U, Strömberg N. Host and bacterial phenotype variation in adhesion of Streptococcus mutans to matched human hosts. Infect Immun. 2012;80:3869-3879.

[59] Crowley PJ, Seifert TB, Isoda R, van Tilburg M, Oli MW, Robinette RA, McArthur WP, Bleiweis AS, Brady LJ. Requirements for surface expression and function of adhesin P1 from Streptococcus mutans. Infect Immun. 2008;76:2456-2468. 
[60] Gibbons RJ, Cohen L, Hay DI. Strains of Streptococcus mutans and Streptococcus sobrinus attach to different pellicle receptors. Infect Immun. 1986;52:555-561.

[61] Gibbons RJ, Hay DI. Adsorbed salivary acidic proline-rich proteins contribute to the adhesion of Streptococcus mutans JBP to apatitic surfaces. J Dent Res. 1989;68:13031307.

[62] Paes Leme AF, Koo H, Bellato CM, Bedi G, Cury JA. The role of sucrose in cariogenic dental biofilm formation-new insight. J Dent Res. 2006;85(10):878-887.

[63] Stephan RM, Hemmens ES. Studies of changes in $\mathrm{pH}$ produced by pure cultures of oral micro-organisms; effects of varying the microbic cell concentration; comparison of different micro-organisms and different substrates; some effects of mixing certain micro-organisms. J Dent Res. 1947;26:15-41.

[64] Duque C, Stipp RN, Wang B, Smith DJ, Höfling JF, Kuramitsu HK, Duncan MJ, MattosGraner RO. Downregulation of $\mathrm{GbpB}$, a component of the VicRK regulon, affects biofilm formation and cell surface characteristics of Streptococcus mutans. Infect Immun. 2011;79: 786-96.

[65] Xiao J, Klein MI, Falsetta ML, Lu B, Delahunty CM, Yates JR $3^{\text {rd }}$, Heydorn A, Koo H. The exopolysaccharide matrix modulates the interaction between $3 \mathrm{D}$ architecture and virulence of a mixed-species oral biofilm. PLoS Pathog. 2012;8:e1002623.

[66] Gimmarinaro P, Paton JC. Role of RegM, a homologue of the catabolite repressor protein CcpA, in the virulence of Streptococcus pneumonia. Infect Immun. 2002;70:54545461.

[67] Hotz J, Hartmann W, Goberna R, Clodi PH. Enzyme substitution. Med Welt. 1972;23:1611-1613.

[68] Gong Y, Tian XL, Sutherland T, Sisson G, Mai J, Ling J, Li YH. Global transcriptional analysis of acid-inducible genes in Streptococcus mutans: multiple two-component systems involved in acid adaptation. Microbiology. 2009;155:3322-3332.

[69] Welin-Neilands J, Svensater G. Acid tolerance of biofilm cells of Streptococcus mutans. Appl Environ Microbiol. 2007;73:5633-5638.

[70] Lemos JA, Burne RA. A model of efficiency: stress tolerance by Streptococcus mutans. Microbiology. 2008;157:3247-3255.

[71] Peterson SN, Snesrud E, Schork NJ, Bretz WA. Dental caries pathogenicity: a genomic and metagenomic perspective. Int Dent J. 2011;61:11-22.

[72] Sheng J, Marquis RE. Enhance acid resistance of oral streptococci at lethal pH values associated with acid-tolerant catabolism and with ATP synthase activity. FEMS Microbiol lett. 2006;262:93-98. 
[73] Svensäter G, Sjögreen B, Hamilton IR. Multiple stress responses in Streptococcus mutans and the induction of general and stress-specific proteins. Microbiology. Jan; 2000;146:107-117.

[74] Fozo EM, Scott-Anne K, Koo H, Quivey RG Jr. Role of unsaturated fatty acid biosynthesis in virulence of Streptococcus mutans. Infect Immun. 2007;75:1537-1539.

[75] Hata S, Mayanagi H. Acid diffusion through extracellular polysaccharides produced by various mutants of Streptococcus mutans. Arch Oral Biol. 2003;48:431-438.

[76] Santiago B, MacGilvray M, Faustoferri RC, Quivey RG. The branched-chain amino acid aminotransferase encoded by ilvE is involved in acid tolerance in Streptococcus mutans. J Bacteriol. 2012;194:2010-2019.

[77] Len AC, Harty DW, Jacques NA. Proteome analysis of Streptococcus mutans metabolic phenotype during acid tolerance. Microbiology. 2004;150:1353-1366.

[78] Marsh PD, Moter A, Devine DA. Dental plaque biofilms: communities, conflict and control. Peridontology. 2000. 2011;55:16-35.

[79] Wilkins JC, Homer KA, Beighton D. Analysis of Streptococcus mutans proteins modulated by culture under acidic conditions. Appl Environ Microbiol. 2002;68:2382-2390.

[80] Schachtele CF, Mayo JA. Phosphoenolpyruvate-dependent glucose transport in oral streptococci. J Dent Res. 1973;52:1209-1215.

[81] Ge J, Catt DM, Gregory RL. Streptococcus mutans surface $\alpha$-enolase binds salivary mucin MG2 and human plasminogen. Infect Immun. 2004;72:6748-6752.

[82] Nilsson M, Christiansen N, Hoiby N, Twetman S, Givskov M, Tolkier-Nielsen T. A mariner transposon vector adapted for mutagenesis in oral streptococci. Mirobiology Open. 2014;3:333-340.

[83] Jung CJ, Yeh CY, Shun CT, Hsu RB, Cheng HW, Lin CS, Chia JS. Platelets enhance biofilm formation and resistance of endocarditis-inducing streptococci on the injured heart valve. J Infect Dis. 2012;205:1066-1075.

[84] Nomura R, Hamada M, Nakano K, Nemoto H, Fujimoto K, Ooshima T. Repeated bacteraemia caused by Streptococcus mutans in a patient with Sjogren's syndrome. J Med Microbiol. 2007;56:988-992.

[85] Fujiwara T, Nakano K, Kawaguchi M, Ooshima T, Sobue S, Kawabata S, Nakagawa I, Hamada S. Biochemical and genetic characterization of serologically untypable Streptococcus mutans strains isolated from patients with bacteremia. Eur J Oral Sci. 2001;109:330-334.

[86] Nakano K, Nomura R, Matsumoto M, Ooshima T. Roles of oral bacteria in cardiovascular diseases - from molecular mechanisms to clinical cases: cell-surface structures of novel serotype k Streptococcus mutans strains and their correlation to virulence. J Pharmacol Sci. 2010;113:120-125. 
[87] Ioannidis O, Kakoutis E, Katsifa H, Rafail S, Chatzopoulos S, Kotronis A, Makrantonakis N. Streptococcus mutans: a rare cause of retroperitoneal abscess. Adv Med Sci. 2011;56:113-118.

[88] Huang R, Li M, Ye M, Yang K, Xu X, Gregory RL. Effects of nicotine on Streptococcus gordonii growth, biofilm formation, and cell aggregation. Appl Environ Microbiol. 2014;80:7212-7218. DOI: 10.1128/AEM.02395-14.

[89] Ahn SJ, Burne RA. Effects of oxygen on biofilm formation and the AtlA autolysin of Streptococcus mutans. J Bacteriol. 2007;189:6293-6302.

[90] Eglan PG, Palmer RJ Jr, Kolenbrander PE. Interspecies communication in Streptococcus gordonii - Veillonella atypica biofilms: signaling in flow conditions requires juxtaposition. PNAS. 2004;101:16917-16922.

[91] Struzycka I. The oral microbiome in dental caries. Pol J Microbiol. 2014;63(2):127-35.

[92] Koo H, Xiao J, Klein MI, Jeon JG. Exopolysaccharides produced by Streptococcus mutans glucosyltransferases modulate the establishment of microcolonies within multispecies biofilms. J Bacteriol. 2010;192:3024-3032.

[93] Peterson BW, van der Mei HC, Sjollema J, Busscher HJ, Sharma PK. A distinguishable role of eDNA in the viscoelastic relaxation of biofilms. mBio, 2013;4:e00497-13.

[94] Montanaro L, Poggi A, Visai L, Ravaioli S, Campoccia D, Speziale P, Arciola CR. Extracellular DNA in biofilms. Int J Artif Organs. 2011;34:824-831.

[95] Ajdić D, McShan WM, McLaughlin RE, Savić G, Chang J, Carson MB, Primeaux C, Tian R, Kenton S, Jia H, Lin S, Qian Y, Li S, Zhu H, Najar F, Lai H, White J, Roe BA, Ferretti JJ. Genome sequence of Streptococcus mutans UA159, a cariogenic dental pathogen. Proc Natl Acad Sci USA. 2002;99:14434-14439.

[96] Harrington DJ. Bacterial collagenases and collagen-degrading enzymes and their potential role in human disease. Infect Immun. 1996;64:1885-1891.

[97] Marsh PD. Role of the oral microflora in health. Microb Ecol Health Dis. 2000;12:130137.

[98] Tyler BM, Cole MF. Effect of IgA1 protease on the ability of secretory IgA1 antibodies to inhibit the adherence of Streptococus mutans. Microbiol Immunol. 1998;42:503508.

[99] Hajishenngallis G, Nikolova E, Russell MW. Inhibition of Streptococcus mutans adherence to saliva-coated hydroxyapatite by human secretory immunoglobulin A (SIgA) antibodies to cell surface protein antigen I/II: reversal by IgA1 protease cleavage. Infect Immun. 1992;60:5057-5064.

[100] Ogawa A, Furukawa S, Fujita S, Mitobe J, Kawarai T, Narisawa N, Sekizuka T, Kuroda M, Ochiai K, Ogihara H, Kosono S, Yoneda S, Watanabe H, Morinaga Y, Uematsu H, 
Senpuku H. Inhibition of Streptococcus mutans biofilm formation by Streptococcus salivarius FruA. Appl Environ Microbiol. 2011;77:1572-1580.

[101] Goh SY, Khan SA, Tee KK, Abu Kasim NH, Yin WF, Chan KG. Quorum sensing activity of Citrobacter amalonaticus L8A, a bacterium isolated from dental plaque. Sci Rep. 2016;6:20702. DOI: 10.1038/srep20702.

[102] Leung V, Dufour D, Lévesque CM. Death and survival in Streptococcus mutans: differing outcomes of a quorum-sensing signaling peptide. Front Microbiol. 2015;6:1176. DOI: 10.3389/fmicb.2015.01176. eCollection 2015.

[103] Zhang S. Dental caries and vaccination strategy against the major cariogenic pathogen, Streptococcus mutans. Curr Pharm Biotechnol. 2013;14:960-966.

[104] Zhang K, Ou M, Wang W, Ling J. Effects of quorum sensing on cell viability in Streptococcus mutans biofilm formation. Biochem Biophys Res Commun. 2009;379:933938.

[105] Senadheera D, Cvitkovitch DG. Quorum sensing and biofilm formation by Streptococcus mutans. Adv Exp Med Biol. 2008;631:178-188.

[106] Sztajer H1, Lemme A, Vilchez R, Schulz S, Geffers R, Yip CY, Levesque CM, Cvitkovitch DG, Wagner-Döbler I. Autoinducer-2-regulated genes in Streptococcus mutans UA159 and global metabolic effect of the luxS mutation. J Bacteriol. 2008;190:401-415.

[107] Mahajan A, Singh B, Kashyap D, Kumar A, Mahajan P. Interspecies communication and peridontal disease. Sci World J. 2013;2013:765434. DOI: 10.1155/2013/765434. eCollection 2013.

[108] Kołwzan B. Analysis of biofilms - their formation and functioning. Environmental Pollution Control 2011;33:3-14.

[109] Koo H, Falsetta ML, Klein MI. The exopolysaccharide matrix: a virulence determinant of cariogenic biofilm. J Dent Res. 2013;XX:1-9.

[110] Klein MI, Falsetta ML, Xiao J, Bowen WH, Koo H. The role of extracellular polysaccharides matrix in virulent oral biofilms. In: Oral Microbial Ecology: Current Research and New Perspectives, Jakubovics NS, Palmer RJ Jr (editors) Caister Academic Press, Norfolk, UK. 2013; 63-84.

[111] Kuboniwa M, Tribble GD, Hendrickson EL, Amano A, Richard JL, Hackett M. Insights into the virulence of oral biofilms: discoveries from proteomics. Expert Rev Proteomisc. 2012;9:311-323.

[112] Liu J, Wu C, Huang I-H, Merritt J, Qi F. Differential response of Streptococcus mutans towards friend and foe in mixed-species cultures. Microbiology. 2011;157:2433-2444.

[113] Wang B-Y, Deutch A, Hong J, Kuramitsu HK. Proteases of an early colonizer can hinder Streptococcus mutans colonization in vitro. J Dent Res. 2011;90:201-505. 
[114] Tamura S, Yonezawa H, Motegi M, Nakao R, Yoneda S, Watanabe H, Yamazaki T, Senpuku H. Inhibiting effects of Streptococcus salivarius on competence-stimulating peptide-dependent biofilm formation by Streptococcus mutans. Oral Microbiol Immun. 2009;24:125-161.

[115] Kara D, Luppens SBI, van Marle J, Ozok R, ten Cate JM. Microstructural differences between single-species and dual-species biofilms of Streptococcus mutans and Veillonella parvula before and after exposure to chlorhexidine. FEMS Microbiol Lett. 2007;271:9097.

[116] Standar K, Kreikemeyer B, Redanz S, Munter WJ, Laue M, Podbielski A. Setup of an in vitro test system for basic studies on biofilm behavior of mixed-species cultures with dental and peridontal pathogens. PLoS ONE. 2010;5:e13135.

[117] Redanz S, Standar K, Podbielski A, Kreikemeyer B. A five-species transcriptome array for oral mixed-biofilm studies. PLoS ONE. 2011;6:e27827.

[118] Liu L, Tong H, Dong H. Function of the pyruvate oxidase-lactate oxidase cascade in interspecies competition between Streptococcus oligofermentas and Streptococcus mutans. Appl Environ Microbiol. 2012;78:2120-2127.

[119] Jakubovics NS, Gill SR, Vickerman MM, Kolenbrander PE. Role of hydrogen peroxiden competition and cooperation between Streptococcus gordonii and Actinomyces naeslundii. FEMS Microbiol Ecol. 2008;66:367-379.

[120] de Soet JJ. Dissertation 25 years after date 42. Dental caries and the role of specific bacteria. Ned Tijdschr Tandheelkd. 2015;122:525-531. DOI: 10.5177/ntvt.2015.10.15177.

[121] Hossain MS, Biswas I. Mutacins from Streptococcus mutans UA159 are active against multiple streptococcal species. Appl Environ Microbiol. 2011;77:2428-2434.

[122] Kamiya RU, Taiete T, Gonealves RB. Mutacons of Streptococcus mutans. Braz J Microbiol. 2011;42:1248-1258.

[123] Kreth J, Zhang J, Herzberg MC. Streptococcal antagonism in oral biofilms: Streptococcus sanguinis and Streptococcus gordonii interfernce with Streptococus mutans. J Bacteriol. 2008;190:4632-4640.

[124] Wang W, Tao R, Tong Z, Ding Y, Kuang R, Zhai S, Liu J, Ni L. Effect of a novel antimicrobial peptide chrysophsin-1 on oral pathogens and Streptococcus mutans biofilms. Peptides. 2012;33:212-219.

[125] Cheng L, Weir MD, Zhang K, Xu SM, Chen Q, Zhou X, Xu HHK. Antibacterial Nanocomposite with Calcium Phosphate and Quaternary Ammonium. Dentres. 2012;91: 460.

[126] Cheng L, Weir MD, Zhang K, Wu EJ, Xu SM, Zhou X, Xu HH. Dental plaque microcosm biofilm behavior on calcium phosphate nanocomposite with quaternary ammonium. Dent Mater. 2012;28:853-862. 
[127] Lee VA, Karthikeyan R, Rawls HR, Amaechi BT. Anti-cariogenic effect of a cetylpyridinium chloride-containing nanoemulsion. J Dent. 2010;38:742-749.

[128] Cheng L, Zhang K, Weir MD, Liu H, Zhou X, Xu HH. Effects of antibacterial primers with quaternary ammonium and nano-silver on Streptococcus mutans impregnated in human dentin blocks. Dent Mater. 2013;29:462-472. DOI: 10.1016/j.dental.2013.01.011.

[129] Zhang K, Cheng L, Imazato S, Antonucci JM, Lin NJ, Lin-Gibson S, Bai Y, Xu HH. Effects of dual antibacterial agents MDPB and nano-silver in primer on microcosm biofilm, cytotoxicity and dentine bond properties. J Dent. 2013;41:464-474. DOI: 10.1016/j.jdent. 2013.02.001.

[130] Kim YJ, Lee DY, Lee JY, Lim YK. The effect of silver ion-releasing elastomers on mutans streptococci in dental plaque. Korean J Orthod. 2012;42:87-93.

[131] You C, Han C, Wang X, Zheng Y, Li Q, Hu X, Sun H. The progress of silver nanoparticles in the antibacterial mechanism, clinical application and cytotoxicity. Mol Biol Rep. 2012;39:9193-9201.

[132] Mei ML1, Chu CH, Low KH, Che CM, Lo EC. Caries arresting effect of silver diamine fluoride on dentine carious lesion with S. mutans and L. acidophilus dual-species cariogenic biofilm. Med Oral Patol Oral Cir Bucal. 2013;18:e824-31.

[133] Milgrom P, Chi DL. Prevention-centered caries management strategies during critical periods in early childhood. J Calif Dent Assoc. 2011;39:735-741.

[134] Chu CH, Mei L, Seneviratne CJ, Lo EC. Effects of silver diamine fluoride on dentine carious lesions induced by Streptococcus mutans and Actinomyces naeslundii biofilms. Int J Paediatr Dent. 2012;22:2-10.

[135] Chen CY, Chung YC. Antibacterial effect of water-soluble chitosan on representative dental pathogens Streptococcus mutans and Lactobacilli brevis. J Appl Oral Sci. 2012;20:620-627.

[136] Wang W, Tao R, Tong Z, Ding Y, Kuang R, Zhai S, Liu J, Ni L. Effect of a novel antimicrobial peptide chrysophsin-1 on oral pathogens and Streptococcus mutans biofilms. Peptides. 2012;33:212-219. DOI: 10.1016/j.peptides.2012.01.006.

[137] Pepperney A, Chikindas ML. Antibacterial peptides: opportunities for the prevention and treatment of dental caries. Probiotics Antimicrob Proteins. 2011;3:68. DOI: 10.1007/ s12602-011-9076-5.

[138] Frenkel ES, Ribbeck K. Salivary mucins protect surfaces from colonization by cariogenic bacteria. Appl Environ Microbiol. 2015;81:332-338. DOI: 10.1128/AEM.02573-14.

[139] Huo L, Zhang K, Ling J, Peng Z, Huang X, Liu H, Gu L. Antimicrobial and DNA-binding activities of the peptide fragments of human lactoferrin and histatin 5 against Streptococcus mutans. Arch Oral Biol. 2011;56:869-876. DOI: 10.1016/j.archoralbio. 2011.02.004. Epub 2011 Mar 5. 
[140] Helmerhorst EJ, Van't Hof W, Veerman EC, Simoons-Smit I, Nieuw Amerongen AV. Synthetic histatin analogues with broad-spectrum antimicrobial activity. Biochem J. 1997;326:39-45.

[141] Groenink J, Ruissen AL, Lowies D, van 't Hof W, Veerman EC, Nieuw Amerongen AV. Degradation of antimicrobial histatin-variant peptides in Staphylococcus aureus and Streptococcus mutans. J Dent Res. 2003;82:753-757.

[142] Alvarez-Sieiro P, Montalbán-López M, Mu D, Kuipers OP. Bacteriocins of lactic acid bacteria: extending the family. Appl Microbiol Biotechnol. 2016 Feb 10. [Epub ahead of print].

[143] Tong Z, Ni L, Ling J. Antibacterial peptide nisin: a potential role in the inhibition of oral pathogenic bacteria. Peptides. 2014;60:32-40. DOI: 10.1016/j.peptides.2014.07.020.

[144] Bajjar MB, Kashtanov D, Chikindas ML. Natural antimicrobials e-Poly-L-lysine and nisin A for control of oral microflora. Probiotics and Antimicro Prot. 2009;1:143-147.

[145] Merritt J, Qi F. The mutacins of Streptococcus mutans: regulation and ecology. Mol Oral Microbiol. 2012;27:57-69. DOI: 10.1111/j.2041-1014.2011.00634.x.

[146] Shafiei Z, Shuhairi NN, Md Fazly Shah Yap N, Harry Sibungkil CA, Latip J. Antibacterial Activity of Myristica fragrans against Oral Pathogens. Evid Based Complement Alternat Med. 2012;2012:825362. DOI: 10.1155/2012/825362.

[147] Noumedem JA, Mihasan M, Lacmata ST, Tefan M, Kuiate JR, Kuete V. Antibacterial activities of the methanol extracts of ten Cameroonian vegetables against gramnegative multidrug-resistant bacteria. BMC Complement Altern Med. 2013;13:26.

[148] Chen MH. Update on dental nanocomposites. J Dent Res. 2010;89:549-560.

[149] Durani P, Leaper D. Povidone-iodine: use in hand disinfection, skin preparation and antiseptic irrigation. Int Wound J. 2008;5:376-387.

[150] Anderson MJ, Horn ME, Lin YC, Parks PJ, Peterson ML. Efficacy of concurrent application of chlorhexidine gluconate and povidone iodine against six nosocomial pathogens. Am J Infect Control. 2010;38:826-831.

[151] Hosaka Y, Saito A, Maeda R, Fukaya C, Morikawa S, Makino A, Ishihara K, Nakagawa T. Antibacterial activity of povidone-iodine against an artificial biofilm of Porphyromonas gingivalis and Fusobacterium nucleatum. Arch Oral Biol. 2012;57:364368.

[152] Simratvir M, Singh N, Chopra S, Thomas AM. Efficacy of $10 \%$ Povidone Iodine in children affected with early childhood caries: an in vivo study. J Clin Pediatr Dent. 2010;34:233-238.

[153] Yoshida A, Kuramitsu HK. Multiple Streptococcus mutans are involved in biofilm formation. Appl Environ Microbiol. 2002;68:6283-6291. 
[154] Dalwi F, Spratt DA, Pratten J. Use of quantitative PCR and culture methods to characterize ecological flux in bacterial biofilms. J Clin Microbiol. 2007;45:3072-3076.

[155] Edlund A, Yang Y, Hall AP, Guo L, Lux R, He X, Nelson KE, Nealson KH, Yooseph S, Shi $W$, McLean JS. An in vitro biofilm model system maintaining a highly reproducible species and metabolic diversity approaching that of the human oral microbiome. Microbiome. 2013;1:25. DOI: 10.1186/2049-2618-1-25.

[156] Wade WG. The oral microbiome in health and disease. Pharmacol Res. 2013;69:137143.

[157] Johansson I, Witkowska E, Kaveh B, Lif Holgerson P, Tanner AC. The microbiome in populations with a low and high prevalence of caries. J Dent Res. 2016;95:80-86. DOI: 10.1177/0022034515609554.

[158] Benitez-Paez A, Belda-Ferre P, Mira A. Microbiota diversity and gene expression dynamics in human oral biofilm. BMC Genomics. 2014;15:311-323.

[159] Jiang W, Ling Z, Lin X, Chen Y, Zhang J, Yu J, Xiang C, Chen H. Pyrosequencing analysis of oral microbiota shitfig in vorious caries states in childhood. Microb Ecol. 2014;67:962969.

[160] Zaura E, Keijser BJF, Huse SM, Crielaard W. Defining the healthy "core microbiome" of oral microbial communities. BMC Microbiol. 2009;9:259-270.

[161] Keijser BJF, Zaura E, Huse SM, Van der Vossen JMBM, Schuren FHJ, Montijn RC, ten Cate JM, Crielaard W. Pyrosequencing analysis of the oral microflora of healthy adults. J Dent Res. 2008;87:1016-1020.

[162] Usha C, Sathyanarayanan R. Dental caries - a complete changeover (part I). J Conserv Dent. 2009;12:46-54.

[163] Bowden G. Does assessment of microbial composition of plaque/saliva allow for diagnosis of disease activity of individuals? Community Dent Oral Epidemiol. 1997;25:76-81.DOI:10.1111/j.1600-0528.1997.tb00902.x

[164] Chen H, Jiang W. Application of high-throughput sequencing in understanding human oral microbiome related with health and disease. Front Microbiol. 2014;5:508. DOI: 10.3389/fmicb.2014.00508. Collection Review.

[165] Kashket S, Zhang J, Van Houte J. Accumulation of fermentable sugars and metabolic acids in food particles that become entrapped on the dentition. J Dent Res 1996;75:18851891.DOI:10.1177/00220345960750111101.

[166] Heinrich-Weltzien R, Bartsch B, Eick S. Dental caries and microbiota in children with black stain and non-discoloured dental plaque. Caries Res. 2014;48:118-125.

[167] Jiang W, Zhang J, I Chen H. Pyrosequencing analysis of oral microbiota in children with severe early childhood dental caries. Curr Microbiol. 2013;67:537-542. DOI: 10.1007/s00284-013-0393-7. 
[168] Yang F, Zeng X, Ning K, Liu KL, Lo CC, Wang W, Chen J, Wang D, Huang R, Chang X, Chain PS, Xie G, Ling J, Xu J. Saliva microbiomes distinguish caries-active from healthy human populations. ISME J. 2012;6:1-10. DOI: 10.1038/ismej.2011.71.

[169] Gomar-Vercher S, Cabrera-Rubio R, Mira A, Almerich-Silla J. Relationship of children's salivary microbiota with their caries status: a pyrosequencing study. Clin Oral Investig. 2014;18:2087-2094. DOI: 10.1007/s00784-014-1200-y.

[170] Obata J, Takeshita T, Shibata Y, Yamanaka W, Unemori M, Akamine A, Yamashita Y. Identification of the microbiota in carious dentin lesions using $16 \mathrm{~S}$ rRNA gene sequencing. PLo SONE 2014;9:e103712. DOI:10.1371/journal.pone.0103712.

[171] Costa MT, Dorta ML, Ribeiro-Dias F, Pimenta FC. Biofilms of black tooth stains: PCR analysis reveals presence of Streptococcus mutans. Braz Dent J. 2012;23:555-558.

[172] Kim do K, Kim KH, Cho EJ, Joo SJ, Chung JM, Son BY, Yum JH, Kim YM, Kwon HJ, Kim BW, Kim TH, Lee EW. Gene cloning and characterization of MdeA, a novel multidrug efflux pump in Streptococcus mutans. J Microbiol Biotechnol. 2013;23:430-435.

[173] Koyanagi S, Lévesque CM. Characterization of a Streptococcus mutans intergenic region containing a small toxic peptide and its cis-encoded antisense small RNA antitoxin. PLoS One. 2013;8:e54291.

[174] Lazarevic V, Whiteson K, Huse S, Hernandez D, Farinelli L, Osterås M, Schrenzel J, François P. Metagenomic study of the oral microbiota by Illumina high-throughput sequencing. J Microbiol Methods. 2009;79:266-271. DOI: 10.1016/j.mimet.2009.09.012.

[175] Simsek AD, Sezer S, Ozdemir NF, Mehmet H. Streptococcus vestibularis bacteremia following dental extraction in a patient on long-term hemodialysis: a case report. NDT Plus 2008;1:276-277.

[176] Willcox MD, Knox KW, Green RM, Drucker DB. An examination of strains of the bacterium Streptococcus vestibularis for relative cariogenicity in gnotobiotic rats and adhesion in vitro. Arch Oral Biol. 1991;36:327-333.

[177] Matsumoto M, Tsuji M, Sasaki H, Fujita K, Nomura R, Nakano K, Shintani S, Ooshima T. Cariogenicity of the probiotic bacterium Lactobacillus salivarius in rats. Caries Res. 2005;39:479-483.

[178] Sheng J, Baldeck JD, Nguyen PT, Quivey RG Jr, Marquis RE. Alkali production associated with malolactic fermentation by oral streptococci and protection against acid, oxidative, or starvation damage. Can J Microbiol. 2010;56:539-47. DOI: 10.1139/ w10-039.

[179] Whiley RA, Fraser HY, Douglas CW, Hardie JM, Williams AM, Collins MD. Streptococcus parasanguis sp. nov, an atypical viridans Streptococcus from human clinical specimens. FEMS Microbiol Lett. 1990;56:115-121.

[180] Garnett JA, Simpson PJ, Taylor J, Benjamin SV, Tagliaferri C, Cota E, Chen YY, Wu H, Matthews S. Structural insight into the role of Streptococcus parasanguinis Fap1 within 
oral biofilm formation. Biochem Biophys Res Commun. 2012;417:421-426. DOI: 10.1016/j.bbrc.2011.11.131.

[181] Becker MR, Paster BJ, Leys EJ, Moeschberger ML, Kenyon SG, Galvin JL, Boches SK, Dewhirst FE, Griffen AL. Molecular analysis of bacterial species associated with childhood caries. J Clin Microbiol. 2002;40:1001-1009.

[182] Liu B, Zhu F, Wu H, Matthews S. NMR assignment of the amylase-binding protein A from Streptococcus parasanguinis. Biomol NMR Assign. 2015;9:173-175. DOI: 10.1007/ s12104-014-9568-9.

[183] Krzyściak W, Pluskwa KK, Piątkowski J, Krzyściak P, Jurczak A, Kościelniak D, Skalniak A. The usefulness of biotyping in the determination of selected pathogenicity determinants in Streptococcus mutans. BMC Microbiol. 2014;14:194. DOI: 10.1186/1471-2180-14-194.

[184] Ma C, Chen F, Zhang Y, Sun X, Tong P, Si Y, Zheng S. Comparison of oral microbial profiles between children with severe early childhood caries and caries-free children using the human oral microbe identification microarray. PLoS One. 2015;10:e0122075. DOI: 10.1371/journal.pone.0122075. eCollection 2015.

[185] van der Hoeven JS, Mikx FH, Plasschaert AJ, Maltha JC. Experimental periodontal disease in rats induced by plaque-forming microorganisms. J Periodontal Res. 1975;10:143-147.

[186] Noorda WD, Purdell-Lewis DJ, van Montfort AM, Weerkamp AH. Monobacterial and mixed bacterial plaques of Streptococcus mutans and Veillonella alcalescens in an artificial mouth: development, metabolism, and effect on human dental enamel. Caries Res. 1988; 22:342-347.

[187] Zhou J, Jiang N, Wang S, Hu X, Jiao K, He X, Li Z, Wang J. Exploration of Human Salivary Microbiomes-Insights into the Novel Characteristics of Microbial Community Structure in Caries and Caries-Free Subjects. PLoS One. 2016;11:e0147039. DOI: 10.1371/journal.pone.0147039. eCollection 2016.

[188] Gao X, Jiang S, Koh D, Hsu CY. Salivary biomarkers for dental caries. Periodontol. 2000. 2016;70:128-141. DOI: 10.1111/prd.12100.

[189] Rogers AH. Studies on fusobacteria associated with periodontal diseases. Aust Dent J. 1998;43:105-109.

[190] Lee SE, Nam OH, Lee HS, Choi SC. Diversity and homogeneity of oral microbiota in healthy Korean pre-school children using pyrosequencing. Acta Odontol Scand. 2016 Jan 12:1-2. [Epub ahead of print].

[191] Ping X, Gunsolley J. Application of metagenomics in understanding oral health and disease. Virulence. 2014;5:424-432. DOI:10.4161/viru.28532. 